\title{
Numerical Study of the Origin and Stability of Chemically Distinct Reservoirs Deep in Earth's Mantle
}

P. van Thienen ${ }^{(1), *}$, J. van Summeren ${ }^{(1)}$, R.D. van der Hilst ${ }^{(1,2)}$, A.P. van den Berg ${ }^{(1)}$, and N.J. Vlaar $^{(1)}$

(1) Institute of Earth Sciences, Utrecht University, Utrecht, The Netherlands

(2) Department of Earth, Atmospheric and Planetary Sciences, Massachusetts Institute of Technology, Cambridge, MA

* presently at: Institut de Physique du Globe de Paris, 4 avenue de Neptune, Saint-Maur-des-Fossés, France

Seismic tomography is providing mounting evidence for large scale compositional heterogeneity deep in Earth's mantle, and also the diverse geochemical and isotopic signatures observed in oceanic basalts suggest that the mantle is not chemically homogeneous. Isotopic studies on Archean rocks indicate that mantle inhomogeneity may have existed for most of the Earth's history. One important component may be recycled oceanic crust, residing at the base of the mantle. We investigate, by numerical modeling, if such reservoirs may have been formed in the early Earth, before plate tectonics (and subduction) were possible, and how they have survived - and evolved - since then. During Earth's early evolution, thick basaltic crust may have sunk episodically into the mantle in short but vigorous diapiric resurfacing events. These sections of crust may have resided at the base of the mantle for very long times. Entrainment of material from the enriched reservoirs thus produced may account for EM and HIMU signatures in oceanic basalts, whereas deep subduction events may have shaped and replenished deep mantle reservoirs. Our modeling shows that (1) convective instabilities and resurfacing may have produced deep enriched mantle reservoirs prior to the era of plate tectonics, that (2) such formation is qualitatively consistent with the geochemical record showing multiple distinct OIB sources, and that (3) reservoirs thus produced may be stable for billions of years.

\section{INTRODUCTION}

Understanding mantle convection and the relationships with plate tectonic motion at Earth's surface and heat loss from Earth's deep interior remains one of the most challenging objectives in global geophysics. For many decades the discussions centered on canonical end-member models of strict layering or unhindered whole mantle flow, but over the past decade cross-disciplinary research has gradually shifted the paradigm toward a class of hybrid models that combine certain aspects of the classical models. Reconciling constraints from different research disciplines remains difficult, however.

Geochemical analysis of mid-ocean ridge basalts (MORB) and ocean island basalts (OIBs) have been used to argue for the long term survival of compositionally distinct domains in Earth's mantle. The arguments have been reviewed extensively elsewhere [e.g. Hofmann, 1997; Davies, 2002; Albarède and Van der Hilst, 2002; Anderson, 2002b; Harrison and Ballentine, 2005, this volume]; here we mention only a few observations. Sampling issues aside, the surprisingly uniform trace element composition of MORBs suggests their derivation from a well-mixed source (typically referred to as the depleted MORB mantle or DMM). In contrast, OIB analyses have revealed a markedly more diverse pattern, resulting in a rich nomenclature that includes enriched mantle 1 and 2 (EM-1 and EM-2) and HIMU, which has high- $\mu={ }^{238} \mathrm{U} /{ }^{204} \mathrm{~Pb}$ (see Table 1) and the postulation of several distinct geochemical reservoirs [e.g. Zindler and Hart, 1986; Hofmann, 1997; Harrison and Ballentine, 2005, this volume]. The longevity of some of these reservoirs (apparent age up to 2.5 billion years), and, thus, their relative stability against re-mixing, was inferred from lead isotope dating [Chase, 1978; Tatsumoto, 1978; Allègre and Lewin, 1995]. 'Primitive' He ratios observed in OIBs may suggest 
input from an undifferentiated mantle source, but this interpretation has been questioned [Porcelli and Halliday, 2001; Meibom et al., 2003]. Furthermore, the energy balance between heat production, heat loss, and planetary cooling, is often used to argue for 'hidden' reservoirs of enhanced heat production [e.g. Kellogg et al., 1999, and references therein], although there is some uncertainty about the heat flux out of the core.

The presence of distinct mantle reservoirs is consistent with cosmogenic arguments and heterogeneous accretion models of Earth's formation [e.g. Anderson, 2002a; Righter, 2005, this volume] and with mounting evidence for compositional heterogeneity in the deep mantle from seismic tomography [Creager and Jordan, 1986; Van der Hilst and Kárason, 1999; Masters et al., 2000; Saltzer et al., 2001, 2004; Trampert et al., 2004; Trampert and Van der Hilst, 2005, this volume]. Collectively, this evidence suggests that instead of whole mantle convection a kind of layered or zoned convection is more realistic.

Traditional layered convection models assumed that the $660 \mathrm{~km}$ discontinuity between upper and lower mantle formed such a reservoir boundary. However, seismic tomography shows subducting slabs crossing the $660 \mathrm{~km}$ discontinuity and sinking into the deeper mantle beneath several convergent margins, which suggests that the boundary between the different chemical reservoirs cannot be this discontinuity [Van der Hilst et al., 1997]. In an attempt to break away from canonical - and unsuccessful - end-member models of unhindered whole mantle convection or strict stratification at $660 \mathrm{~km}$ depth, Van der Hilst and Kárason [1999] and Kellogg et al. [1999] postulated the existence of compositional layering in the deep lower mantle and explored its gravitational stability. Their results show that a deep layer with a relative chemical density contrast of $4 \%$ is stable, although significant topography may develop. The effective density contrast may approach zero, however, because of the higher internal temperature of the layer due to enhanced internal heating. Numerical models by Hansen and Yuen [1988, 2000], with the latter using a larger aspect ratio of their model domain, advecting heat sources, and strongly temperature and pressure dependent viscosity, and by Tackley [2002] (using a 3D model), as well as the analog experiments by Davaille [1999] also show the development of the deep dense layer with significant topography. Numerical experiments by Samuel and Farnetani [2003] and Samuel and Farnetani [2005](this volume), which include trace element fractionation and degassing leading to distinct helium signatures, show that a chemical density excess of only $2.4 \%$ may be sufficient to stabilize a deep layer.

Absent strong seismological evidence for a well defined layer, several alternative configurations of these main reservoirs have been proposed [see e.g. Tackley, 2002, for a review], with the part of the deep mantle that contains more primitive material capped by enriched recycled crust [Hofmann, 1997; Coltice and Ricard, 1999, and references therein], the enriched crustal reservoir residing at the core-mantle boundary with a layer or mounds of primitive mantle on top [Christensen and Hofmann, 1994; Hansen and Yuen, 2000; Tackley, 2000], a layer of enriched crustal material at the CMB with pockets of primitive mantle residing throughout the mantle [Becker et al., 1999], and an unstratified but heterogeneous mantle in which depleted mantle and subducted lithosphere are continuously mixed [Allègre and Turcotte, 1986; Helffrich and Wood, 2001]. Recognizing the lack of evidence for global seismic interfaces anywhere between $660 \mathrm{~km}$ and the top of the so called $D^{\prime \prime}$ layer, Albarède and Van der Hilst [2002] proposed zoned mantle convection, a modification of the model by Kellogg and co-workers, in which variable depth subduction sets up a radial gradient in mantle mixing and which may leave the lowermost mantle largely exempt from convective overturn.

In addition to demonstrating conclusively its existence, its nature, and volume, there are two fundamental questions regarding our understanding of deep mantle heterogeneity. First, when and how was it formed? Second, how did it evolve over long periods of geological time?

Several origins of compositional heterogeneity in Earth's deep mantle have been proposed. Interaction of liquid iron from the outer core with silicates in the lowermost mantle may produce a heavy phase in the lowermost mantle [Knittle and Jeanloz, 1991; Guyot et al., 1997]. However, the effect on major element composition of present-day core-mantle interaction is likely to be confined to a relatively small region above the core mantle boundary and cannot explain the seismically observed compositional heterogeneity in the bottom $1000 \mathrm{~km}$ of the mantle [Van der Hilst and Kárason, 1999; Trampert et al., 2004; Trampert and Van der Hilst, 2005, this volume]. According to Scherstén et al. [2004], tungsten isotopes in OIBs rule out a core contribution to their source, but their conclusion 
is somewhat controversial [see Jellinek and Manga, 2004], and evidence to the contrary has been reported also [Humayun et al., 2004]. The formation of a deep reservoir by perovskite fractionation in a magma ocean, suggested by Agee and Walker [1988], is not compatible with geochemical evidence [Halliday et al., 1995; Blichert-Toft and Albarède, 1997]. The sinking of subducted slabs of former oceanic lithosphere into the lower mantle may add enriched crustal material to a hypothetical reservoir somewhere in the lower mantle. Christensen and Hofmann [1994] showed by numerical modeling that this could produce the range of isotopic ratios found in oceanic basalts. Albarède and Van der Hilst [2002] suggested that in a zoned mantle an enriched reservoir, possibly of early origin, could be replenished and maintained by selective deep subduction of enriched, eclogitic oceanic plateau crust.

While plate tectonics is unlikely to have been important in a hot early Earth [Sleep and Windley, 1982; Vlaar, 1985; Vlaar and Van den Berg, 1991; Van Thienen et al., 2004c], there are geochemical indications of the existence of distinct reservoirs in the early Earth. It is most likely that the earliest Archean rocks found on Earth have been derived from an already depleted mantle [e.g. Hamilton et al., 1983; Patchett, 1983; Vervoort et al., 1996; Blichert-Toft et al., 1999]. The age of this differentiation has been found from Lu-Hf data to be at least 4.08 Gyr before present [Amelin et al., 2000]. Sm-Nd data indicate an even older mean age of differentiation: $4.460 \pm 0.115$ Ga [Caro et al., 2003]. Hf isotopes in carbonatites and kimberlites from Greenland and North America of up to 3 Gyr of age indicate derivation of these rocks from an enriched mantle source with an unradiogenic Hf signature [low ${ }^{176} \mathrm{Hf} /{ }^{177} \mathrm{Hf}$, Bizzarro et al., 2002]. Van Thienen et al. [2004b] proposed that prior to plate tectonics the necessary fluxes could have taken place in the form of the episodic rapid sinking of complete segments of crust ( $>1000 \mathrm{~km}$ long) into the mantle.

In this paper, we describe and model two dynamic regimes, representative for the early and presentday Earth, that we think are important for producing and maintaining deep mantle heterogeneity. In this paper we do not attempt to study the transition between these regimes. Building on previous work [Van Thienen et al., 2004b], we investigate the possibility of an early Earth formation of a deep enriched mantle reservoir by convective instabilities (diapirism). Subsequently, we use numerical convection experiments to investigate the long-term dynamical behaviour and stability of such a reservoir and to evaluate the geochemical characteristics. We remark that in the context of our experiments the term 'stability' is used to indicate that the deep layer survives on a time scale of billions or years. Processes are studied in the context of a transient mantle dynamic regime, and predictions from our models are compared with geochemical constraints.

\section{NUMERICAL MODELS: GENERAL METHODOLOGY}

In separate numerical experiments we investigate the formation of enriched deep mantle reservoirs under thermal conditions representative of the early Earth and the long-term evolution and stability of such deep mantle reservoirs. Before discussing Experiments I and II in more detail we here describe the general numerical elements.

We use a mantle convection code based on the finite element package SEPRAN [Segal and Praagman, 2000; Van den Berg et al., 1993] to solve the energy, Stokes, and continuity equations in the extended Boussinesq approximation [e.g. Steinbach et al., 1989]:

$$
\begin{gathered}
\rho c_{p}\left(\frac{\partial T}{\partial t}+u_{j} \partial_{j} T\right)-\alpha T \frac{d p}{d t}= \\
\tau_{i j} \partial_{j} u_{i}+\partial_{j}\left(k \partial_{j} T\right)+\rho_{0} H+\frac{\Delta S}{c_{p}} \frac{d F}{d t} T+\sum_{k} \frac{\gamma_{k} \delta \rho_{k} T}{\rho_{0}^{2} c_{p}} \frac{d \Gamma_{k}}{d t}, \\
\partial_{j} \tau_{i j}-\partial_{i} \Delta p+\Delta \rho g_{i}=0, \\
\partial_{j} u_{j}=0 .
\end{gathered}
$$


For symbol definitions, see Tables 2 and 3.

For numerical purposes, equations (1)-(3) are transformed into their non-dimensional equivalents using the following scaling:

$$
T=\Delta T \cdot T^{\prime}, x_{i}=h \cdot x_{i}^{\prime}, t=\frac{h^{2}}{\kappa} \cdot t^{\prime}, u_{i}=\frac{\kappa}{h} \cdot u_{i}^{\prime}, p=\frac{\eta_{0} \kappa}{h^{2}} \cdot p^{\prime}, \tau=\frac{\eta_{0} \kappa}{h^{2}} \tau^{\prime}
$$

with the parameters as listed in Table 2 and the primes indicating dimensionless parameters.

Flow is driven by density perturbations, which are related to variations of temperature, composition, and phase, and are described by the equation of state:

$$
\Delta \rho=\rho_{0}\left\{-\alpha\left(T-T_{r e f}\right)+\sum_{k} \Gamma_{k} \frac{\delta \rho_{k}}{\rho_{0}}+\frac{\delta \rho}{\rho_{0}} F\right\}
$$

The second term inside the braces of equation (5) describes the effect of solid state phase transitions of mantle peridotite around $670 \mathrm{~km}$ (in experiments I and II) and $400 \mathrm{~km}$ (experiment I) depth. This term also includes the effects of solid state phase transitions of basaltic material, see below. The last term in brackets describes the effect of chemical depletion due to partial melting, see below.

\section{EXPERIMENT I: EARLY FORMATION OF DEEP MANTLE RESERVOIRS}

In this section we investigate by geodynamical modeling Earth's early differentiation and the formation of a deep reservoir enriched in incompatible trace elements by downward transport and deep storage of oceanic crust. Because of resolution requirements we limit the computational domain to a depth of $1200 \mathrm{~km}$, thus focusing on the processes of crust production and recycling that take place at the surface and in the relatively shallow mantle.

\subsection{Numerical Aspects of Experiment I}

\subsubsection{Model description}

In Experiment I (see Table 4) deformation is controlled by a composite rheology [Van den Berg et al., 1993], which includes diffusion creep, dislocation creep, and a stress limiter mechanism [Van den Berg et al., 1993; Van Hunen et al., 2002]. We also consider partial melting and melt segregation and their effects on diffusion and dislocation creep. Following Van Thienen et al. [2003], the effect of partial melting is controlled by a parameter called the degree of depletion $F$, which indicates the mass fraction of melt removed from a control volume of mantle rock. The parameter values used in Experiment I are given in Table 5.

Diffusion and dislocation creep are described by an Arrhenius relation [Karato and Wu, 1993; Van den Berg and Yuen, 1998]:

$$
\eta_{i}=f(F) B_{i} \exp \left[\frac{E_{i}+P V_{i}}{R T}\right] \tau^{1-n_{i}},
$$

with proportionality factor $f(F)$ representing the effect of partial melting (see below). A stress limiter mechanism is included to approximate brittle failure of the lithosphere. It is implemented according to Van Hunen et al. [2002]: 


$$
\eta_{y}=\tau_{y} \dot{\varepsilon}_{y}^{-1 / n_{y}} \dot{\varepsilon}^{\left(1 / n_{y}\right)-1}
$$

where the normal yield strength $\tau_{y}$ is approximated in Byerlee's law with the lithostatic pressure [e.g. Moresi and Solomatov, 1998]:

$$
\tau_{y}=C_{0}+\mu \rho g z
$$

To simulate the effect on viscosity of dehydration during partial melting of mantle material (model run I-a, Table 4), $f(F)$ in equation 6 is varied linearly between 1 and 10 for values of the $F$ between 0.005 and 0.05 [Karato, 1986; Hirth and Kohlstedt, 1996; Mei and Kohlstedt, 2000a, b]. We set $f$ to a constant value of 1 for $F<0.005$ and to 10 for $F>0.05$. For eclogite we use $f=0.1$ because of the lower flow strength of omphacite [Piepenbreier and Stöckhert, 2001]. For the partial melting of basaltic crust (model run I-b, Table 4) we apply the solidus and liquidus of a hydrated tholeiite using data from Green [1982].

In our numerical experiments partial melting occurs when the equilibrium degree of depletion $F$ corresponding to the local pressure and temperature conditions is higher than the actual local degree of depletion. We assume complete melt extraction but we do not account for compaction of the residual rock. Upon melt extraction an equivalent amount of basaltic material is added at the top boundary of the model (inflow boundary condition) directly above the region of partial melting, where it is assumed to be hydrated.

Upon partial melting, the local incompatible trace element concentration is adjusted according to a batch melting model with a bulk partition coefficient of $10^{-2}$, comparable to that of $\mathrm{K}$ and somewhat greater than that of $\mathrm{U}$ and Th [Henderson, 1982; Beattie, 1993]. This results in a concentration of trace elements in the basaltic crust. The local rate of radiogenic heat production is proportional to the incompatible trace element concentration.

In our models, the basaltic crustal material produced by partial melting of mantle peridotite undergoes solid state phase transitions at $30 \mathrm{~km}$ depth (transformation to eclogite, with a relaxation time of $1.25 \mathrm{Myr}$ ) and $400 \mathrm{~km}$ depth. The latter transition corresponds to the decomposition of omphacite which results in an increase of the garnet content[see Irifune and Ringwood, 1993; Okamoto and Maruyama, 2004], and to the transformation of coesite into stishovite [see Aoki and Takahashi, 2004]. In our model these transitions are combined and assumed to occur instantaneously. Although the actual depth of the basalt to eclogite phase transition is closer to $40 \mathrm{~km}$ [1.2 GPa, Hacker, 1996], garnet starts to be formed from about 0.7 to $0.8 \mathrm{GPa}$ [Green and Ringwood, 1967; Ito and Kennedy, 1971; Hacker, 1996], raising the density of the assemblage above that of basalt. We note, however, that an increase of ten $\mathrm{km}$ in transformation depth results in similar model dynamics and would therefore not effect the conclusions of the research reported here. We prescribe an excess density of eclogite relative to undepleted peridotite of $200 \mathrm{kgm}^{-3}$, similar to that used in earlier numerical studies [Dupeyrat and Sotin, 1995; Van Hunen et al., 2002]. A lower excess density would result in a stretching of the time scale of the resurfacing process, whereas a higher excess density would speed it up.

The density inversion between eclogite and peridotite below $670 \mathrm{~km}$ depth [e.g. Ringwood and Irifune, 1988; Irifune and Ringwood, 1993] is not taken into account. Numerical experiments by [Christensen, 1988] suggest that no long-term trapping of eclogite in this zone is expected. New petrological data by Hirose et al. [1999] show that the inferred density inversion zone is narrower than reported earlier (with the lower boundary at 720 rather than $800 \mathrm{~km}$ depth), and the positive Clapeyron slope of the lower bounding transition would cause a further narrowing for cool subducting material. On the basis of these results, Hirose et al. [1999] also expect no significant trapping of basaltic material in this zone. 


\subsubsection{Model domain and initial and boundary conditions}

Approximately 5100 quadratic elements were used to discretize the domain, measuring $1200 \times 1200$ $\mathrm{km}$, for solving the energy and momentum equations (1)-(3). The chemical evolution was evaluated by means of approximately 350000 active particle tracers.

An initial condition was obtained by the internal heating (extreme rate of $250 \cdot 10^{-12} \mathrm{Wkg}^{-1}$ ) of a pristine subsolidus mantle to high temperatures, whereby a crust was formed by partial melting of the convecting mantle. The composition and temperature field at the time a $30 \mathrm{~km}$ crust had been produced was taken as the initial condition for the main numerical experiment (see Plate 1a), with the internal heating reduced to $15 \cdot 10^{-12} \mathrm{Wkg}^{-1}$, scaled by the local trace element concentration and decaying with time (see Table 2). This internal heating rate corresponds to Bulk Silicate Earth values around 3.5-4.0 Gyr before present [Van Schmus, 1995]. Note that the layered convection in the initial situation is produced by the model and not prescribed explicitly.

The vertical boundaries have a periodic boundary condition. The top boundary has a prescribed temperature of $0^{\circ} \mathrm{C}$, a tangential stress-free condition, and a prescribed inflow velocity corresponding to the amount of basaltic crust being produced by partial melting of the underlying mantle. The lower boundary has a free-slip condition and is thermally insulated. This latter point results in an absence of plumes from the deep lower mantle. However, deep mantle plumes can be expected to affect the positioning of sinking crust rather than its rate of accumulation. Therefore we do not expect this to significantly influence our results. It will affect the stability of the deep dense layer once it has been formed. This will be the subject of investigation in the second series of experiments.

\subsection{Large Scale Resurfacing in Earth's Early Evolution}

Results of numerical experiment I-a (Table 4) are presented in Plate 1. The column on the left shows the composition field at six different times. The color scale indicates the degree of depletion of mantle peridotite, ranging from fertile (blue) to depleted (orange). Black tracers are used to monitor the basaltic material, and red tracers represent eclogite. White arrows illustrate the instantaneous flow field. The corresponding temperature field is shown on the right; the color scale indicates local temperature and the contours depict regions of partial melting.

Plate $1 \mathrm{~b}$ shows that in the first 70 million yr of model evolution small-scale delamination of the lower crust results in the mixing of small amounts of eclogitic lower crust into the upper mantle [see Van Thienen et al., 2004b].

Around 170 Myr (Plate 1c), a locally thickened section of crust, largely transformed into eclogite, starts to sink into the mantle; in doing so it pulls thinner neighboring crust along with it, which initiates a resurfacing event. New crust is being produced near the sinking crustal section by partial melting of complementary upwelling mantle material (see melting contour in temperature plot). The resurfacing process continues until the sinking crust breaks off, at which time - and in this model run - some $1500 \mathrm{~km}$ of crust has been pulled into the mantle.

Plate $1 \mathrm{~d}$ shows the crustal material sinking into the lower mantle, forcing lower mantle material into the upper mantle. The subsequent frames show the eclogite body settling on the bottom boundary. Because of its high content of radiogenic trace elements, it heats up relatively quickly (Plate 1f).

\subsection{Trace Element Evolution}

The secular evolution of the distribution of a (hypothetical) incompatible trace element (partition coefficient $10^{-2}$ ) is illustrated in Plate 2. The data shown are corrected for radioactive decay, such that only the effects of fractionation are visible in this figure. The panels show snapshots of the entire computational domain. Yellow regions are depleted relative to the initial uniform composition, and grey/blue regions depicting enrichment. Red and green curves indicate the location of the phase boundaries for peridotite (red) and basalt (green) at 10\% (dashed), 50\% (solid), and $90 \%$ (dashed) 
of the transition.

After $\sim 120$ million yr of model evolution, the upper mantle is somewhat depleted by the extraction of an enriched basaltic crust, with the highest degree of trace element depletion occurring in the shallow upper mantle; the lower mantle, which at this early stage in model evolution convects separately from the upper mantle, is still pristine. Continued partial melting gradually depletes the upper mantle, some exchange of material between the upper and lower mantle takes place, including small blobs of delaminated eclogite (grey).

The resurfacing event which is illustrated in Plate 1 is clearly visible around 170 Myr. During the 50 million years that follow, the old, enriched crust slowly sinks to the bottom of the model mantle, where it remains stable.

The final situation in terms of incompatible trace elements shows: (a) an enriched basaltic crust; (b) a highly depleted shallow mantle; (c) a moderately depleted deep upper mantle and lower mantle, in which small blobs of enriched eclogite (grey spots) are present; (d) an enriched reservoir at the bottom boundary of the mantle.

\subsection{The Effect of Continental Crust Production}

Using the instantaneous composition and temperature field of model I-a at the onset of the resurfacing event, between (b) and (c) of Plate 1, model I-b was computed at a higher resolution in a 600x600 $\mathrm{km}$ domain [upper right quarter of model I-a, see Van Thienen et al., 2004a, for more details]. In this model, partial melting of the basaltic crust was included. The purpose of this numerical experiment is to investigate the effect of this additional melting process on the trace element geochemistry of the material which eventually forms the deep dense layer. Note that the reduction of the Rayleigh number by the reduction of the domain size (see Table 4) does not significantly affect the resurfacing event. The resulting model development is illustrated in Plate 3. Plate 3a-c show only (meta-) basaltic and felsic material. Felsic material, indicated in green, is produced by the partial melting of hydrous (meta-) basalt. This results in depletion of the source rock (purple). Undifferentiated (meta-) basalt is indicated in black. The major part of the sinking crust consists of undepleted metabasalt, but significant amounts of felsic material and depleted metabasalt are also present. The corresponding trace element concentration plots (Plate 3d-f) show that both undepleted and felsic material are enriched in incompatible trace elements relative to undifferentiated mantle peridotite. (Meta-) basalt which has undergone partial melting shows depletion.

\section{EXPERIMENT II: LONG TERM STABILITY OF DEEP MANTLE RESER- VOIRS}

In numerical experiment II (see Table 4 for parameter settings of the different model runs) we consider the long-term behavior of compositionally distinct deep mantle domains. We assume that at the start of the model calculations such domains had already been formed, for instance by the mechanism

discussed above. Because the formation process is not modeled, we need less resolution than in the previous numerical experiments and can include the entire depth of the mantle.

\subsection{Numerical Aspects of Experiment II}

\subsubsection{Model description}

In contrast to Experiment I, partial melting and fractionation of trace elements are not included in Experiment II. Since dislocation creep is predominant at relatively low pressures only [Karato and Li, 1992; Van den Berg and Yuen, 1996] we ignore this deformation mechanism in our study of the long term dynamic behavior of intrinsically dense domains in the lower mantle. Instead, we include a pressure and temperature dependent Newtonian viscosity: 


$$
\eta(T, z)=100 \eta_{0} \exp [-\ln (20) \cdot T+\ln (100) \cdot z]
$$

An endothermic phase transition around $660 \mathrm{~km}$ is defined using a negative Clapeyron slope of $\gamma=d p / d T=-2.5 \cdot 10^{6} \mathrm{PaK}^{-1}$. Since this is believed to be the main obstacle for material exchange between the upper and lower mantle and since here we do not aim to produce a detailed picture of the transition zone dynamics, no phase transitions other than at $660 \mathrm{~km}$ have been modeled.

The deep mantle reservoir has a variable excess intrinsic density (see Table 4). Table 4 also lists the various distributions of the internal heating rate between the deep reservoir and the overlying material ( $H_{e n r}$ and $H_{\text {depl }}$ respectively). In all numerical experiments, the heat productivity integrated over the total mantle volume has the same value. This value was chosen such that the volume averaged heat productivity has the chondritic value of $5.0 \cdot 10^{-12} \mathrm{Wkg}^{-1}$ after a $4.5 \mathrm{Gyr}$ period of radioactive decay (half-life time $=2.5 \mathrm{Gyr}$ ). Then it was scaled with a factor 0.629 to correct for an exaggerated heat production that would result from an overestimation of the mantle volume due to the 2-D, Cartesian geometry of the model (as its mantle is much shallower, this effect is not so important in experiment I). We note that the thermal expansivity $\alpha$ decreases with a factor 5 over the depth range of the model (see Table 2 and Table 3).

\subsubsection{Model domain and initial and boundary conditions}

Our Cartesian box model scales to having a depth of $2900 \mathrm{~km}$. An aspect ratio of 2.5 is applied. The numerical mesh contains 250,000 tracers that were initially placed at random locations over a total of 11,000 finite elements.

Free-slip conditions exist on all model boundaries. A temperature of $0^{\circ} \mathrm{C}$ is prescribed at the surface. On the vertical boundaries, reflecting temperature boundary conditions exist. At the bottom boundary, which represents the CMB, a thermal coupling with the core is implemented by prescribing the time dependent core-mantle boundary temperature $T_{C M B}(t)$ equal to the temperature of an isothermal heat reservoir, which is cooled by the CMB heat flux, calculated from the finite element mantle model. The heat capacity of the core heat reservoir is set to a fraction $X=0.8$ of the mantle heat capacity.

The initial model conditions were chosen in order to simulate a hot early Earth where chemical layering in the lowermost mantle is already present. A deep mantle reservoir is prescribed as a flat layer that occupies the lower $20 \%$ of the mantle volume.

Initially, the temperature field represents a uniform hot mantle of $4000^{\circ} \mathrm{C}$, which has been cooled for $60 \mathrm{Myr}$ from the top boundary in order to prevent undesirable large temperature variations. A positive and negative temperature perturbation were added in the upper right and left corners of the domain, inducing convective circulation.

\subsection{Evolution and Stability of Compositional Layering}

\subsubsection{Evolving flow regimes}

We use Model II-e to describe the most important characteristics of the models examined. The calculated composition, temperature, stream function contours, and viscosity field are given in the snapshots at five different times in the model evolution in Plate 4. Figure 1 shows time series of the temperature, viscosity, flow velocity, heat flow, and entrainment rate (defined as the amount of primitive material that resides above the chemical interface relative to the total amount of primitive material present).

During the first 2 Gyr model time, convection is strictly layered at the $660 \mathrm{~km}$ phase transition, preventing material exchange between the upper and lower mantle (see Plate 4b). At these early 
times, the vigour of convection in the mid-mantle (the part of the lower mantle above the deep mantle reservoir) is too small to cause significant topography on the deep mantle reservoir.

Upon further cooling of the upper mantle (Figure 1a,d) the mantle downwellings grow larger and stronger (Plate $4 \mathrm{~b}$, Figure 1c,f), and some of them are now able to break through the phase transition and penetrate the lower mantle (Plate 4c). The inferred breakdown of layered mantle convection is in accord with results by Steinbach et al. [1993]. In our numerical experiments, the time to the change in dynamic regime depends mainly on the cooling rate of the upper mantle and varies between 1 and 2.2 Gyr: in model II-e it starts around 2 Gyr. The downwellings that penetrate the lower mantle produce pronounced flow velocities and large material fluxes across the phase transition (Plate 4b, $1 \mathrm{~b}, \mathrm{e})$. They also create topography on the deep mantle reservoir, which at times is swept into isolated piles (Plate 4d,e). Plate 4e shows that after some 4.5 Gyr of model evolution, a partially layered convection regime has set in, with some cold downwellings temporarily obstructed by the endothermic phase transition near $670 \mathrm{~km}$ depth.

In this model, the cool downwelling material remains mostly on top of the deep dense layer. The presence of the deep mantle reservoir thus limits the amount of contact between the relatively cold downwellings and the hot core, which results in thermal blanketing of the core (Figure 1a,d,g). At the relatively high temperatures in the deep mantle, the material originating from the surface heats up and eventually rises back to the surface in the form of mantle plumes (Plate 4d), entraining material from the bottom high density reservoir. Entrainment is a possible explanation for the typical chemical signature in ocean island basalts [Zhong and Hager, 2003] as was also shown in Samuel and Farnetani [2003], where different chemical components were explicitly modeled in a numerical evolutionary mantle model.

\subsubsection{Long term stability of the deep domains}

In our computer simulations, the stability of compositional layering is controlled by a time dependent buoyancy number $B(t)$, which gives the ratio of the positive thermal buoyancy relative to negative compositional buoyancy:

$$
B=\frac{1}{\alpha_{0} \delta T(t)} \cdot \frac{\delta \rho_{c}}{\rho_{0}}
$$

where $\delta \rho_{c}$ is the compositional density difference and $\delta T(t)$ the time-dependent temperature difference between the deep layer and the overlying mantle. We carried out systematic variations to model II-e in order to investigate the effects on layer stability of variations in excess compositional density and heat productivity in the deep mantle reservoir. The relevant parameters are listed in Table 4.

The time series of $B(t)$, calculated using equation 10, is shown in Figure 1h. It shows that initially, when there is no temperature difference between the two reservoirs, the buoyancy number has a large value. When temperature differences appear, the value of $B(t)$ drops and layer stability decreases. Plate 5 shows snapshots of the composition and temperature field after 4.5 Gyr model time for models II-a, b, c, and d. These models were selected to illustrate the fate of the primitive reservoir when stability decreases.

The topography of the layer is small if the intrinsic density of the layer is large, and global layering as was proposed by Kellogg et al. [1999] is observed (model II-e in Plate 4). When the stability decreases, the deep reservoir is pushed aside by cold downwellings and is swept into isolated piles, as modeled by Hansen and Yuen [2000] and Tackley [2000] (model II-c in Plate 5c). Further reduction of stability leads to a regime where the primitive material is present as blobs of material floating in the lower mantle (model II-b in Plate 5b), which can be compared with the work of Becker et al. [1999]. Ultimately, under conditions least favoring stability, total mixing occurs (model II-a in Plate $5 \mathrm{a})$.

The effects of density and heat productivity distribution on layer stability are examined separately. As a measure for stability, the mean depth of tracers that initially are placed in the deep mantle 
reservoir (with composition $C_{e n r}$ ) is used. The mean depth of $C_{e n r}$-tracers is calculated at every time step as

$$
z_{C_{e n r}}=\frac{1}{n} \sum_{i=1}^{n} z_{i}
$$

where $n$ is the amount of $C_{e n r}$-tracers, and $z_{i}$ is depth of the i-th tracer. To give a reference for interpreting this mean depth we note that in the initial condition $z_{C_{e n r}}=0.9$ and for total mixing $z_{C_{e n r}}=0.5$.

In Figure 2a the mean depth evolution is compared for models II-a, b, c and d, which all have a uniform heat production. The density jump $\frac{\delta \rho_{c}}{\rho_{0}}$ varies from 0.0 to 0.015 .

Figure 2a shows that the mean depth for all models starts at $z=.9$ as was expected. Then, after cold downwellings penetrate the lower mantle and induces layer instability, the mean depth becomes shallower. For subsequently smaller values of the density jump, the deviation from the initial condition is bigger, indicating less stable layering. In Figure $2 \mathrm{~b}$ the mean depth is compared for models with a uniform density jump of .01 and a heat production ration $\frac{H_{e n r}}{H_{d e p l}}$ that varies between 1 and 100 . With increasing enrichment of the deep mantle reservoir, stability decreases as is illustrated by the shallower mean depth of the tracers.

Figure 3 shows a domain diagram indicating which models are stable or instable in the $\frac{\delta \rho_{c}}{\rho_{0}}-\frac{H_{e n r}}{H_{d e p l}}$ space. In agreement with previous studies (e.g., Kellogg et al. [1999]) the diagram shows a clear trade-off between density contrast and excess heat productivity in controlling the long-term stability of the internal layering.

\subsection{Sensitivity to the Postspinel Clapeyron Slope}

Most mantle convection models which include solid state phase transitions apply a Clapeyron slope of around $-2.5 \mathrm{MPa} / \mathrm{K}$ for the postspinel phase transition, consistent with several petrological [e.g. Bina and Helffrich, 1994; Hirose, 2002] and seismological [e.g. Lebedev et al., 2002] studies. Recently, however, Katsura et al. [2003] have shown that the slope may in fact have a smaller magnitude, probably in the range of -0.4 to $-2.0 \mathrm{MPa} / \mathrm{K}$. In order to investigate the effect of a reduction of the magnitude of the Clapeyron slope of the postspinel phase transition on the stability of a deep dense layer, we have conducted a series of experiments for a range of Clapeyron slopes, with a fixed $1 \%$ $\delta \rho / \rho_{0}=0.01$ and $H_{e n r} / H_{\text {depl }}=10$. The results are presented in Plate 6 (snapshots after $\sim 4.4 \mathrm{Gyr}$ of evolution) and Figure 2c (time series of average vertical coordinate of dense tracers).

Figure 2c shows that for a low value of the Clapeyron slope of 0 and $-1.25 \mathrm{MPa} / \mathrm{K}$, respectively, the dense layer starts mixing through the mantle around 1 Gyr after the start of the models, and is more or less completely mixed after 4.5 Gyr. This picture is also shown by Plate $6 \mathrm{a}$,b, which shows that nonetheless the heavy tracers are not uniformly mixed throughout the mantle. For a stronger phase transition $(\gamma=-2.5 \mathrm{MPa} / \mathrm{K})$, we observe the survival of part of the deep dense layer after 4.5 Gyr in the form of a mound. Survival is near complete for the highest Clapeyron slope of -3.75 $\mathrm{MPa} / \mathrm{K}$.

Clearly, the ability of cold downwelling from the upper mantle to penetrate into the (deep) lower mantle strongly affects the mixing of the deep layer through the mantle. As is illustrated by Plate 4b,c and Figure 1e, the transition of completely layered to partially layered convection is accompanied by an increase in the root mean square velocity, and cold downwellings cause significant topography in the deep layer (Plate 4d,e). 


\section{DISCUSSION AND CONCLUDING REMARKS}

\section{$5.1 \quad$ Transient Dynamical Regimes}

Model series I and II both show a transient behavior. In model I-a, the initial hot phase is characterized by layered mantle convection and the formation of a thick basaltic crust. Exchange of material between the upper and lower mantle and the sinking of crustal sections into the lower mantle break this layered convection on a relatively short timescale of $\mathrm{O}\left(10^{8} \mathrm{yr}\right)$. The progressed cooling of the model results in the production of a thinner and more stable crust, and because of the absence of a sharp temperature contrast between upper and lower mantle due to whole mantle convection and lack of fertile mantle material, lower mantle diapirism inducing large-scale melting events no longer takes place. A transition to plate tectonics would be expected here, though the model is incapable of reproducing plate tectonics. Because of the small extent of this model, characteristic time scales of cooling and thus transition between regimes are short compared to the Earth.

Around 1 to 2 Gyr, model II-e shows a transition from layered mantle convection to a mode of convection where the phase transition acts as a filter to subducting slabs, which results in cold downwellings reaching the deep mantle and disturbing the compositional layering. This observation is qualitatively consistent with some interpretations of the geochemical record: on the basis of geochemical mass balances of large-ion-lithophile (incompatible) elements such as $\mathrm{Sr}, \mathrm{Nd}$ and $\mathrm{Hf}$ and noble gas isotope systems, Allègre [1997] argued that the transition to whole mantle convection may have started some 0.5 Gyr ago.

The ultimate stability of the primitive reservoirs depends on the initially prescribed parameters, which directly and indirectly control the excess density of the deep layer. This is illustrated by Figure 3 , which shows stable layering for large excess chemical densities of the lower layer and low internal heating rates, and instability for small density contrasts at high internal heating rates.

\subsection{Reconciliation With Isotope Geochemistry}

By numerical modeling we have explored a mechanism for the formation and deep mantle storage of enriched crustal material (see Plate 1). Plate 3 demonstrates that significant amounts of mafic (metabasalt) material, perhaps corresponding to the HIMU source, are transported to the base of the mantle. Christensen and Hofmann [1994] also found that, in a plate tectonic like model, significant volumes of subducted crust may settle at the base of the mantle and contribute to $\mathrm{Pb}$ and $\mathrm{Nd}$ isotope ratios which correspond to observed values in the MORB to HIMU spectrum.

Tatsumi $[2000 \mathrm{~b}]$ proposed that the EM-1 reservoir may have been formed by the accumulation of delaminated pyroxenitic restite from which continental material had been extracted, produced between 4 and 3 Ga by partial melting of arc basalts. He supported this hypothesis by calculating the corresponding isotopic evolution for $\mathrm{Nd}$ and $\mathrm{Pb}$ isotopes assuming $45 \%$ and $60 \%$ of batch melting, resulting in pyroxenitic and eclogitic restites, respectively. He found that a pyroxenitic restite with a $3-4 \%$ andesitic component (interpreted as retained melt in his model) produces an isotopic signature characteristic of EM-1, with low ${ }^{143} \mathrm{Nd} /{ }^{144} \mathrm{Nd},{ }^{207} \mathrm{~Pb} /{ }^{204} \mathrm{~Pb}$, and ${ }^{206} \mathrm{~Pb} /{ }^{204} \mathrm{~Pb}$ (see Table 1) . Although subduction zones are the setting in which this model is thought to have operated [Tatsumi, $2000 \mathrm{~b}, \mathrm{a}]$, we propose that a resurfacing setting such as discussed in section 3.2 is equally valid, with a sinking crust in this context corresponding to a subducting slab in the plate tectonics sense. Significant quantities of basalt are produced in association with recycling of crust (either small-scale delamination or resurfacing), more or less analogous to arc basalts. During a resurfacing event, partial melting of this basalt may take place, equivalent to partial melting associated with delamination in Tatsumi's model. Plate 3 shows that a significant part of the metabasalt which has sunk into the mantle has undergone (varying degrees of) partial melting (pink color). No melt retention is included in our model but, as in Tatsumi's model, some retention is not unlikely.

Alternatively, our model is also consistent with the interpretation of the EM-1 and EM-2 isotopic signatures being caused by recycled continental material [Zindler and Hart, 1986; Chauvel et al., 
1992; Hofmann, 1997], since Plate 3 shows significant amounts of felsic material entrained in the resurfacing event and residing at the bottom of the model domain. The inhomogeneity of the deep material shown in Plate 3 is consistent with the apparent coexistence of different sources in the Earth's mantle which are interpreted for the different types of OIBs (see Table 1).

Most geochemical mantle models include, next to DMM, a reservoir of enriched recycled crust and a primitive undegassed mantle reservoir with a primitive trace element composition and a high ${ }^{3} \mathrm{He} /{ }^{4} \mathrm{He}$ ratio [see Tackley, 2000], but the use of He isotopes in oceanic basalts as an indicator for derivation from a primitive undegassed reservoir has been questioned [Meibom et al., 2003].

In model I-a, no undifferentiated mantle peridotite survives longer than 500 million years of model evolution (see Plate 2). However, the small size of the model domain and its implications of a more rapid cooling of the system result in a reduction of the thermal Rayleigh number $\left(=\rho_{0} \alpha g_{0} \Delta T h^{3} / \eta_{0} \kappa\right)$, which favors the development of single-layer mantle convection over two-layer convection [Christensen and Yuen, 1985]. This would reduce the probability of pristine material to survive. However, the lower velocities associated with the reduced Rayleigh number oppose this effect.

\subsection{Long Term Stability of Deep Mantle Domains}

Although they are sensitive to prior assumptions and model geometry, the results of Experiment II can be used to give a qualitative insight in the dynamics of mantle evolution.

The series of models II shows that a deep, enriched reservoir may be dynamically stable on a 4.5 Gyr time scale, which is in line with previous studies [Kellogg et al., 1999; Hansen and Yuen, 2000; Tackley, 2002; Samuel and Farnetani, 2003; Zhong and Hager, 2003; Nakagawa and Tackley, 2004]. The relative enrichment in heat producing elements as seen in the results of numerical experiment Ia (Plate 2) gives an estimate of the position of Earth on the vertical axis in Figure 3 (that is, between $10^{1}$ and $10^{2}$ ). An estimate of the position on the horizontal axis is more difficult, as the phase relations of basaltic material are poorly known for the deep mantle. But in order to be consistent with the presence of some chemically distinct material in the deep mantle, an excess density of at least $1.5 \%$ seems required. However, for Clapeyron slope magnitudes less than the canonical -2.5 $\mathrm{MPa} / \mathrm{K}$ for the postspinel phase transition, as suggested by recent work of Katsura et al. [2003], cold downwellings from the upper mantle may be too strong and numerous to allow survival of a deep dense layer over billions of years. In our models, the primitive reservoir appears in several forms. For decreasing stability conditions it first appears as a global layer on top of the CMB, transforms into isolated piles and then into blobs, before it would finally mix with the depleted mantle material.

\subsection{Concluding Remarks}

We have presented computer simulations of a possible early formation and the subsequent long term evolution of compositionally distinct domains in Earth's deep interior, and we have shown that these models are in qualitative agreement with the geochemical record; that is, a deep, dense layer consisting of a geochemically inhomogeneous melange is consistent with the presence of distinct types of OIB. From such analysis alone we cannot, however, determine which of the models presented here (if any) is representative for planet Earth. Seismic tomography is producing increasingly convincing evidence for the presence of compositional heterogeneity both on large [Masters et al., 2000; Saltzer et al., 2001; Trampert et al., 2004] and small length scales [Saltzer et al., 2004], see Trampert and Van der Hilst [2005] (this volume) for a review, but studies of scattering of the high frequency seismic wavefield [Vidale et al., 2001; Castle and Van der Hilst, 2003] have, so far, not produced convincing evidence for the type of global interface that one would expect for global layering. In combination, the results from geodynamical modeling, geochemistry, and seismic imaging are consistent with mantle models in which the changes in bulk composition gradually occur over a large depth range (for instance by depth dependent subduction in the zoned convection proposed by Albarède and Van der Hilst [2002]

or in which small scale heterogeneity exists in the mantle above a distinct layer that has a diffuse boundary, significant short wavelength topography, or both. These models are broadly consistent with the mantle model postulated by Kellogg et al. [1999]. Further narrowing the range of plausible mantle 
models requires (1) better seismological constraints on wavespeed and density ratios and on mantle interfaces, and their uncertainties, (2) continued quantitative integration of results from seismology, experimental and theoretical mineral physics, geochemistry, geodynamical modeling, and (3) careful analysis of secular variations in the geological record (e.g., major element basalt chemistry) and comparison with predictions from geodynamical modeling of Earth's differentiation over long periods of geological time.

Acknowledgments We wish to thank Jan Matas, Michael Manga and an anonymous reviewer for constructive criticism which helped improve the paper. Peter van Thienen acknowledges the financial support provided through the European Community's Human Potential Programme under contract RTN2-2001-00414, MAGE. This work was sponsored by the Stichting Nationale Computerfaciliteiten (National Computing Facilities Foundation, NCF) for the use of supercomputer facilities, with financial support from the Nederlandse Organisatie voor Wetenschappelijk Onderzoek (Netherlands Organization for Scientific Research, NWO). Further computational facilities used were funded by ISES (Netherlands Research Centre for Integrated Solid Earth Science) which is gratefully acknowledged.

\section{References}

Agee, C. B., and D. Walker, Mass balance and phase density constraints on early differentiation of chondritic mantle, Earth Plan. Sci. Let., 90, 144-156, 1988.

Albarède, F., and R. D. Van der Hilst, Zoned Mantle Convection, Philos. T. Roy. Soc. A, 360(1800), 2569-2592, 2002.

Allègre, C. J., Limitation on the mass exchange between the upper and lower mantle: evolving convection regime of the Earth, Earth Plan. Sci. Let., 150(1-2), 1-6, 1997.

Allègre, C. J., and E. Lewin, Isotopic systems and stirring times of the earth's mantle, Earth Plan. Sci. Let., 136, 629-646, 1995.

Allègre, C. J., and D. L. Turcotte, Implications of a two-component marble-cake mantle, Nature, 323, 123-127, 1986.

Amelin, Y., D.-C. Lee, and A. N. Halliday, Earlymiddle Archaean crustal evolution deduced from $\mathrm{Lu}-\mathrm{Hf}$ and $\mathrm{U}-\mathrm{Pb}$ isotopic studies of single zircon grains, Geochimica et Cosmochimica Acta, 64 (24), 4205-4225, 2000.

Anderson, D. L., The case for irreversible chemical stratification of the mantle, International Geology Review, 44, 97-116, 2002a.

Anderson, O. L., The power balance at the coremantle boundary, Phys. Earth Planet. Inter., 131, 1-17, $2002 b$.

Aoki, I., and E. Takahashi, Density of MORB eclogite in the upper mantle, Phys. Earth Planet. Inter., 143-144, 129-143, 2004.

Beattie, P., The generation of uranium series disequilibria by partial melting of spinel peridotite: constraints from partitioning studies, Earth Plan. Sci. Let., 117, 379-391, 1993.

Becker, T. W., J. B. Kellogg, and R. J. O'Connell, Thermal constraints on the survival of primitive blobs in the lower mantle, Earth Plan. Sci. Let., 171, 351-365, 1999.
Bina, C. R., and G. Helffrich, Phase transition Clapeyron slopes and transition zone seismic discontinuity topography, J. Geophys. Res., 99(B8), 15,853-15,860, 1994.

Bizzarro, M., A. Simonetti, R. K. Stevenson, and J. David, Hf isotope evidence for a hidden mantle reservoir, Geology, 30(9), 771-774, 2002.

Blichert-Toft, J., and F. Albarède, The Lu-Hf isotope geochemistry of chondrites and the evolution of the mantle-crust system, Earth Plan. Sci. Let., 148, 243-258, 1997.

Blichert-Toft, J., F. Albarède, M. Rosing, R. Frei, and D. Bridgwater, The $\mathrm{Nd}$ and Hf isotopic evolution of the mantle through the Archean. Results from the Isua supracrustals, West Greenland, and from the Birimian terranes of West Africa, Geochimica et Cosmochimica Acta, 63(22), 3901-3914, 1999.

Caro, G., B. Bourdon, J.-L. Birck, and S. Moorbath, ${ }^{146} \mathrm{Sm}^{-142} \mathrm{Nd}$ evidence from Isua metamorphosed sediments for early differentiation of the Earth's mantle, Nature, 423, 428-432, 2003.

Castle, J. C., and R. D. Van der Hilst, Searching for seismic scattering off mantle interfaces between 800 and $2000 \mathrm{~km}$ depth, J. Geophys. Res., 108, 2095, doi:10.1029/2001JB000286, 2003.

Chase, C. G., Oceanic island Pb: two-stage histories and mantle evolution, Earth Plan. Sci. Let., 52, 277-284, 1978.

Chauvel, C., A. W. Hofmann, and P. Vidal, HIMUEM: The French Polynesian connection, Earth Plan. Sci. Let., 110, 99-119, 1992.

Christensen, U. R., Is subducted lithosphere trapped at the $670-\mathrm{km}$ discontinuity?, Nature, 336, 462463, 1988.

Christensen, U. R., and A. W. Hofmann, Segregation of subducted oceanic crust in the convecting mantle, J. Geophys. Res., 99 (B10), 19,867-19,884, 1994. 
Christensen, U. R., and D. A. Yuen, Layered convection induced by phase transitions, J. Geophys. Res., 99, 10,291-10,300, 1985.

Coltice, N., and Y. Ricard, Geochemical observations and one layer mantle convection, Earth Plan. Sci. Let., 174, 125-137, 1999.

Creager, K. C., and T. H. Jordan, Aspherical structure of the core-mantle boundary from pkp travel times, Geophys. Res. Let., 13(13), 1497-1500, 1986.

Davaille, A., Simultaneous generation of hotspots and superswells by convection in a heterogeneous planetary mantle, Nature, 402, 756-760, 1999.

Davies, G. F., Stirring geochemistry in mantle convection models with stiff plates and slabs, Geochimica et Cosmochimica Acta, 66(17), 3125-3142, 2002.

Dupeyrat, L., and C. Sotin, The effect of the transformation of basalt to eclogite on the internal dynamics of Venus, Planetary and Space Science, 43(7), 909-921, 1995.

Green, D. H., and A. E. Ringwood, An experimental investigation of the gabbro to eclogite transformation and its petrological applications, Geochimica et Cosmochimica Acta, 31, 767-833, 1967.

Green, H. T., Anatexis of mafic crust and high pressure crystallization of andesite, in Andesites, edited by R. S. Thorpe, John Wiley and Sons, 1982.

Guyot, F., J. H. Zhang, I. Martinez, J. Matas, Y. Ricard, and M. Javoy, P-V-T measurements of iron silicide (epsilon-FeSi). Implications for silicatemetal interactions in the early Earth, European Journal of Mineralogy, 9(2), 277-285, 1997.

Hacker, B. R., Eclogite formation and the rheology, buoyancy, seismicity and $\mathrm{H}_{2} \mathrm{O}$ content of oceanic crust, in Subduction: Top to Bottom, pp. 337-346, AGU Monogr., 1996.

Halliday, A. N., D.-C. Lee, S. Tommasini, G. R. Davies, C. R. Paslick, J. G. Fitton, and D. E. James, Incompatible trace elements in OIB and MORB and source enrichment in sub-oceanic mantle, Earth Plan. Sci. Let., 133, 379-395, 1995.

Hamilton, P. J., R. K. O'Nions, D. Bridgwater, and A. Nutman, Sm-Nd studies of Archaean metasediments and metavolcanics from West Greenland and their implications for the Earth's early history, Earth Plan. Sci. Let., 62, 263-272, 1983.

Hanan, B. B., and D. W. Graham, Lead and helium isotope evidence from oceanic basalts for a common deep source of mantle plumes, Science, 272, 991-995, 1996.

Hansen, U., and D. A. Yuen, Numerical simulations of thermal-chemical instabilities at the core-mantle boundary, Nature, 334, 237-240, 1988.
Hansen, U., and D. A. Yuen, Extended-Boussinesq thermal-chemical convection with moving heat sources and variable viscosity, Earth Plan. Sci. Let., 176, 401-411, 2000.

Harrison, D., and C. J. Ballentine, Noble gas models of mantle structure and reservoir mass transfer, this volume, 2005.

Hart, S. R., E. H. Hauri, L. A. Oschmann, and J. A. Whitehead, Mantle plumes and entrainment: isotopic evidence, Science, 256, 517-520, 1992.

Hauri, E. H., Osmium isotopes and mantle convection, Phil. Trans. R. Soc. Lond., A 360, 2371-2382, 2002.

Hauri, E. H., and S. R. Hart, Re-Os isotope systematics of HIMU and EMII oceanic island basalts from the south Pacific Ocean, Earth Plan. Sci. Let., 114 , 353-371, 1993.

Helffrich, G. R., and B. J. Wood, The Earth's Mantle, Nature, 412, 501-507, 2001.

Henderson, P., Inorganic geochemistry, Pergamon, 1982.

Hirose, K., Phase transitions in pyrolitic mantle around $670-\mathrm{km}$ depth:Implications for upwelling of plumes from the lower mantle, J. Geophys. Res., 107(B4), doi:10.1029/2001JB000597, 2002.

Hirose, K., Y. Fei, Y. Ma, and H.-K. Mao, The fate of subducted basaltic crust in the earth's lower mantle, Nature, 397, 53-56, 1999.

Hirth, G., and D. L. Kohlstedt, Water in the oceanic upper mantle: implications for rheology, melt extraction and the evolution of the lithosphere, Earth Plan. Sci. Let., 144, 93-108, 1996.

Hofmann, A. W., Mantle geochemistry: the message from oceanic volcanism, Nature, 385, 219-229, 1997.

Humayun, M., L. Qin, and M. D. Norman, Geochemical evidence for excess iron in the mantle beneath Hawaii, Science, 306, 91-94, 2004.

Irifune, T., and A. E. Ringwood, Phase transformations in subducted oceanic crust and buoyancy relations at depths of $600-800 \mathrm{~km}$ in the mantle, Earth Plan. Sci. Let., 117, 101-110, 1993.

Ito, K., and G. C. Kennedy, An experimental study of the basalt-garnet granulite-eclogite transition, in The structure and physical properties of the Earth's crust, edited by J. G. Heacock, pp. 303-314, American Geophysical Union, Washington D. C., 1971.

Jellinek, A. M., and M. Manga, Links between longlived hot spots, mantle plumes, D", and plate tectonics, Rev. of Geophysics, 42(RG3002), doi: 10.1029/2003RG000144, 2004.

Karato, S., Does partial melting reduce the creep strength of the upper mantle?, Nature, 319, 309310,1986 . 
Karato, S.-I., and P. Li, Diffusion creep in perovskite: implications for the rheology of the lower mantle, Science, 255, 1238-1240, 1992.

Karato, S.-i., and P. Wu, Rheology of the upper mantle: a synthesis, Science, 260, 771-778, 1993.

Katsura, T., et al., Post-spinel transition in $\mathrm{Mg}_{2} \mathrm{SiO}_{4}$ determined by high $\mathrm{P}-\mathrm{T}$ in situ X-ray diffractometry, Phys. Earth Planet. Inter., 136, 11-24, 2003.

Kellogg, L., B. H. Hager, and R. D. Van der Hilst, Compositional Stratification in the Deep Mantle, Science, 283, 1881-1884, 1999.

Knittle, E., and R. Jeanloz, Earth's core-mantle boundary: results of experiments at high pressures and temperatures, Science, 251, 1438-1443, 1991.

Lebedev, S., S. Chevrot, and R. D. Van der Hilst, Seismic evidence for olivine phase transitions near 410 and 660-kilometers depth, Science, 296, 13001302, 2002.

Masters, G., G. Laske, H. Bolton, and A. Dziewonski, The relative behavior of shear velocity, bulk sound speed, and compressional velocity in the mantle; implications for chemical and thermal structure, in Earth's deep interior; mineral physics and tomography from the atomic to the global scale, edited by S.-I. Karato, A. M. Forte, R. C. Liebermann, G. Masters, and L. Stixrude, pp. 63-86, American Geophysical Union, Washington, DC, 2000.

Mei, S., and D. L. Kohlstedt, Influence of water on plastic deformation of olivine aggregates 1: Diffusion creep regime, J. Geophys. Res., 105, 21,45721,469, 2000a.

Mei, S., and D. L. Kohlstedt, Influence of water on plastic deformation of olivine aggregates 2: Dislocation creep regime, J. Geophys. Res., 105, 21,47121,481, 2000b.

Meibom, A., D. L. Anderson, N. H. Sleep, R. Frei, C. P. Chamberlain, T. H. Hren, and J. L. Wooden, Are high ${ }^{3} \mathrm{He} /{ }^{4} \mathrm{He}$ ratios in oceanic basalts an indicator of deep-mantle plume components, Earth Plan. Sci. Let., 208, 197-204, 2003.

Moresi, L., and V. Solomatov, Mantle convection with a brittle lithosphere: thoughts on the global tectonic styles of the Earth and Venus, Geophys. J. Int., 133, 669-682, 1998.

Nakagawa, T., and P. Tackley, Thermo-chemical structure in the mantle arising from a threecomponent convective system and implications for geochemistry, Phys. Earth Planet. Inter., 2004.

Okamoto, K., and S. Maruyama, The eclogitegarnetite transformation in the $\mathrm{MORB}+\mathrm{H}_{2} \mathrm{O}$ system, Phys. Earth Planet. Inter., 146, 283-296, 2004 .
Patchett, P. J., Importance of the Lu-Hf isotopic system in studies of planetary chronology and chemical evolution, Geochimica et Cosmochimica Acta, 47, 81-91, 1983.

Piepenbreier, D., and B. Stöckhert, Plastic flow of omphacite in eclogites at temperatures below $500^{\circ} \mathrm{C}$ - implications for interplate coupling in subduction zones, Int. J. Earth Sciences, 90, 197-210, 2001.

Porcelli, D., and A. N. Halliday, The core as a possible source of mantle helium, Earth Plan. Sci. Let., 192, 45-56, 2001.

Righter, Highly siderophile elements: constraints on Earth accretion and early differentiation, this volume, 2005.

Ringwood, A. E., and T. Irifune, Nature of the 650$\mathrm{km}$ seismic discontinuity; implications for mantle dynamics and differentiation, Nature, 331(6152), 131-136, 1988.

Saltzer, R., R. D. Van der Hilst, and H. Kárason, Comparing $\mathrm{P}$ and $\mathrm{S}$ wave heterogeneity in the mantle, Geophys. Res. Let., 28, 1335-1338, 2001.

Saltzer, R. L., R. Stutzmann, and R. D. Van der Hilst, Poisson's ration beneath Alaska from the surface to the Core-Mantle Boundary, J. Geophys. Res., 109, doi:10.1029/2003JB002712, 2004.

Samuel, H., and C. G. Farnetani, Thermochemical convection and helium concentrations in mantle plumes, Earth Plan. Sci. Let., 107, 39-56, 2003.

Samuel, H., and C. G. Farnetani, this volume, 2005.

Scherstén, A., T. Elliot, C. Hawkesworth, and M. Norman, Tungsten isotope evidence that mantle plumes contain no contribution from the Earth's core, Nature, 427, 234-237, 2004.

Segal, A., and N. P. Praagman, The sepran package, Tech. rep., http://dutita0.twi.tudelft.nl/sepran/sepran.html, 2000 .

Sleep, N. H., and B. F. Windley, Archean plate tectonics: constrains and inferences, Journal of Geology, 90, 363-379, 1982.

Steinbach, V., U. Hansen, and A. Ebel, Compressible convection in the Earths mantle - a comparison of different approaches, Geophys. Res. Let., 16(7), 633-636, 1989.

Steinbach, V., D. A. Yuen, and W. Zhao, Instabilities from phase-transitions and the timescales of mantle thermal evolution, Geophys. Res. Let., 20(12), 1119-1122, 1993.

Tackley, P. J., Mantle Convection and Plate Tectonics: Toward an Integrated Physical and Chemical Theory, Science, 288, 2002-2007, 2000.

Tackley, P. J., Strong heterogeneity caused by deep mantle layering, Geochem. Geophys. Geosyst., 3(4), 1024, doi:10.1029/2001GC000167, 2002. 
Tatsumi, Y., Slab melting: its role in continental crust formation and mantle evolution, Geophys. Res. Let., 27(23), 3941-3944, 2000a.

Tatsumi, Y., Continental crust formation by crustal delamination in subduction zones and complementary accumulation of the enriched mantle I component in the mantle, Geochem. Geophys. Geosyst., 1, paper number 2000GC000094, 2000b.

Tatsumoto, M., Isotopic composition of lead in oceanic basalt and its implication to mantle evolution, Tectonophysics, 38, 64-87, 1978.

Trampert, J., and R. D. Van der Hilst, Quantitative interpretation of global seismic tomography, this volume, 2005.

Trampert, J., F. Deschamps, J. Resovsky, and D. A. Yuen, Probabilistic tomography maps significant chemical heterogeneities in the lower mantle, Science, 306 (5697), 853-856, 2004

Van den Berg, A. P., and D. A. Yuen, Is the lowermantle rheology Newtonian today?, Geophys. Res. Let., 23(16), 2033-2036, 1996.

Van den Berg, A. P., and D. A. Yuen, Modelling planetary dynamics by using the temperature at the core-mantle boundary as a control variable: effects of rheological layering on mantle heat transport, Phys. Earth Planet. Inter., 108, 219-234, 1998.

Van den Berg, A. P., P. E. Van Keken, and D. A. Yuen, The effects of a composite non-Newtonian and Newtonian rheology on mantle convection, Geophys. J. Int., 115, 62-78, 1993.

Van der Hilst, R. D., and H. Kárason, Compositional Heterogeneity in the Bottom $1000 \mathrm{~km}$ of the Earth's Mantle: Toward a Hybrid Convection Model, Science, 283, 1885-1888, 1999.

Van der Hilst, R. D., S. Widiyantoro, and E. R. Engdahl, Evidence for deep mantle circulation from global tomography, Nature, 386, 578-584, 1997.

Van Hunen, J., A. P. Van den Berg, and N. J. Vlaar, On the role of subducting oceanic plateaus in the development of shallow flat subduction, Tectonophysics, 352, 317-333, 2002.

Van Schmus, W. R., Natural radioactivity of the crust and mantle, in Global Earth Physics. A handbook of constants, edited by T. J. Ahrens, pp. 283-291, AGU, Washington, 1995.

Van Thienen, P., A. P. Van den Berg, J. H. De Smet, J. Van Hunen, and M. R. Drury, Interaction between small-scale mantle diapirs and a continental root, Geochem. Geophys. Geosyst., 4, 10.1029/2002GC000,338, 2003.
Van Thienen, P., A. P. Van den Berg, and N. J. Vlaar, On the formation of continental silicic melts in thermo-chemical mantle convection models: implications for early Earth, Tectonophysics, 394(12), 111-124, 2004a.

Van Thienen, P., A. P. Van den Berg, and N. J. Vlaar, Production and recycling of oceanic crust in the early earth, Tectonophysics, 386(1-2), 41-65, 2004b.

Van Thienen, P., N. J. Vlaar, and A. P. Van den Berg, Plate tectonics on the terrestrial planets, Phys. Earth Planet. Inter., 142(1-2), 61-74, 2004c.

Vervoort, J. D., P. J. Patchett, G. E. Gehrels, and A. P. Nutman, Constraints on early Earth differentiation from hafnium and neodymium isotopes, Nature, 379, 624-627, 1996.

Vidale, J. E., G. Schubert, and P. S. Earle, Unsuccessful initial search for a midmantle chemical boundary with seismic arrays, Geophys. Res. Let., 28(5), 859-862, 2001.

Vlaar, N. J., Precambrian geodynamical constraints, in The deep proterozoic crust in the North Antlantic provinces, edited by A. C. Tobi and J. L. R. Touret, pp. 3-20, Reidel, 1985.

Vlaar, N. J., and A. P. Van den Berg, Continental evolution and archeao-sea-levels, in Glacial Isostasy, Sea-Level and Mantle Rheology, edited by R. Sabadini, K. Lambeck, and E. Boschi, Kluwer, Dordrecht, Netherlands, 1991.

Zhong, S. J., and B. H. Hager, Entrainment of a dense layer by thermal plumes, Geophys. J. Int., 154(3), 666-676, 2003.

Zindler, A., and S. Hart, Chemical geodynamics, Ann. Rev. Earth Planet. Sci., 14, 493-571, 1986.

P. van Thienen, Département de géophysique spatiale et planétaire, Institut de Physique du Globe de Paris, 4 avenue de Neptune, Saint-Maur-des-Fossés, France; corresponding author, email: thienen@ipgp.jussieu.fr J. van Summeren, Institute of Earth Sciences, Utrecht University, PO Box 80.021, 3508 TA Utrecht, The Netherlands R.D. van der Hilst, Department of Earth, Atmospheric and Planetary Sciences, Massachusetts Institute of Technology, Cambridge, MA 02139, USA A.P. van den Berg, Institute of Earth Sciences, Utrecht University, PO Box 80.021, 3508 TA Utrecht, The Netherlands N.J. Vlaar, Institute of Earth Sciences, Utrecht University, PO Box 80.021, 3508 TA Utrecht, The Netherlands 


\begin{tabular}{|c|c|c|c|c|c|c|c|c|}
\hline source & $\frac{143 \mathrm{Nd}}{1444 \mathrm{Nd}}$ & $\frac{87 \mathrm{Sr}}{86 \mathrm{Sr}}$ & $\frac{{ }^{206} \mathrm{~Pb}}{{ }^{204} \mathrm{~Pb}}$ & $\frac{{ }^{207} \mathrm{~Pb}}{204 \mathrm{~Pb}}$ & $\frac{238 \mathrm{U}}{204 \mathrm{~Pb}}$ & $\frac{187 \mathrm{Os}}{188 \mathrm{Os}^{-18}}$ & $\frac{{ }^{3} \mathrm{He}}{{ }^{4} \mathrm{He}}$ & interpretation \\
\hline DMM & high & low & low & low & & low & & \\
\hline HIMU & $\begin{array}{l}\text { high } \\
(<\mathrm{DMM})\end{array}$ & low & high & high & high & high & & recycled crust \\
\hline EM-1 & low & interm. & low & rel. low & & high & & recycled \\
\hline EM-2 & low & high & low & rel. high & & interm. & & $\begin{array}{l}\text { recycled } \\
\text { continental crust }\end{array}$ \\
\hline $\mathrm{FOZO} / \mathrm{C}$ & high & low & interm. & interm. & & low & high & \\
\hline
\end{tabular}

Table 1: Oceanic basalt source reservoirs and their distinguishing isotopic characteristics. DMM is depleted MORB mantle, HIMU is high- $\mu\left({ }^{238} \mathrm{U} /{ }^{204} \mathrm{~Pb}\right), \mathrm{EM}-1$ and EM-2 are enriched mantle 1 and 2, FOZO is focal zone and C is common. Information compiled from Zindler and Hart [1986], Chauvel et al. [1992], Hart et al. [1992], Hauri and Hart [1993], Hanan and Graham [1996], Hofmann [1997], and Hauri [2002]. 


\begin{tabular}{|c|c|c|}
\hline symbol & property & value/unit \\
\hline $\begin{array}{l}c_{p} \\
F\end{array}$ & $\begin{array}{l}\text { heat capacity at constant pressure } \\
\text { degree of depletion }\end{array}$ & $1250 \mathrm{Jkg}^{-1} \mathrm{~K}^{-1}$ \\
\hline$g$ & gravitational acceleration & $9.8 \mathrm{~ms}^{-2}$ \\
\hline$H$ & radiogenic heat productivity & $\mathrm{Wkg}^{-1}$ \\
\hline$k$ & thermal conductivity & $\mathrm{Wm}^{-1} \mathrm{~K}^{-1}$ \\
\hline$p$ & pressure & $\mathrm{Pa}$ \\
\hline$\Delta p$ & non-hydrostatic pressure perturbation & $\mathrm{Pa}$ \\
\hline$\Delta S$ & entropy change upon full differentiation & $300 \mathrm{Jkg}^{-1} \mathrm{~K}^{-1}$ \\
\hline$t$ & time & $\mathrm{s}$ \\
\hline$T$ & temperature & ${ }^{\circ} \mathrm{C}$ \\
\hline$T_{0}$ & non-dimensional surface temperature & $\frac{273}{\Delta T}$ \\
\hline$u$ & velocity & $\mathrm{ms}^{-1}$ \\
\hline$z$ & depth & $\mathrm{m}$ \\
\hline$z_{0}(T)$ & temperature dependent depth of phase transition & $\mathrm{m}$ \\
\hline$\gamma_{k}$ & Clapeyron slope for transition $k$ & $\mathrm{PaK}^{-1}$ \\
\hline$\Gamma_{k}$ & phase function for transition $k$ & \\
\hline$\delta z$ & depth range of phase transition & $\mathrm{m}$ \\
\hline$\kappa$ & thermal diffusivity & $10^{-6} \mathrm{~m}^{2} \mathrm{~s}^{-1}$ \\
\hline$\rho$ & density & $\mathrm{kgm}^{-3}$ \\
\hline$\delta \rho_{k}$ & density increase of phase transition $k$ & $\mathrm{kgm}^{-3}$ \\
\hline$\tau_{i j}$ & deviatoric stress tensor & $\mathrm{Pa}$ \\
\hline$\tau_{\frac{1}{2}}$ & half life of radiogenic heating & $2.5 \mathrm{Gyr}$ \\
\hline \multicolumn{3}{|c|}{ Experiment I only } \\
\hline$h$ & depth scale & $1200 \cdot 10^{3} \mathrm{~m}$ \\
\hline$\Delta T$ & temperature scale & $2450^{\circ} \mathrm{C}$ \\
\hline$\alpha$ & thermal expansion coefficient & $3 \cdot 10^{-5} \mathrm{~K}^{-1}$ \\
\hline$\eta_{0}$ & viscosity scale & $10^{20} \mathrm{Pas}$ \\
\hline$\rho_{0}$ & reference density & $3416 \mathrm{kgm}^{-3}$ \\
\hline \multirow[t]{5}{*}{$\delta \rho$} & density difference & \\
\hline & peridotite upon full depletion & $-226 \mathrm{kgm}^{-3}$ \\
\hline & basalt & $-416 \mathrm{kgm}^{-3}$ \\
\hline & eclogite & $200 \mathrm{kgm}^{-3}$ \\
\hline & felsic material & $-800 \mathrm{kgm}^{-3}$ \\
\hline \multicolumn{3}{|c|}{ Experiment II only } \\
\hline$h$ & depth scale & $2900 \cdot 10^{3} \mathrm{~m}$ \\
\hline$\Delta T$ & temperature scale & $4000^{\circ} \mathrm{C}$ \\
\hline$\alpha$ & thermal expansion coefficient & $\mathrm{K}^{-1}$ \\
\hline$\alpha_{0}$ & reference thermal expansion coefficient & $2 \cdot 10^{-5} \mathrm{~K}^{-1}$ \\
\hline$\Delta \alpha$ & thermal exp. contrast across mantle & 5 \\
\hline$\eta_{0}$ & viscosity scale & $5 \cdot 10^{20} \mathrm{Pas}$ \\
\hline$\rho_{0}$ & reference density & $3400 \mathrm{kgm}^{-3}$ \\
\hline
\end{tabular}

Table 2: Symbols definitions and parameter values. 


\begin{tabular}{ccl}
\hline symbol & definition & experiment \\
\hline$e_{i j}$ & $\partial_{j} u_{i}+\partial_{i} u_{j}$ & I,II \\
$e$ & {$\left[\frac{1}{2} e_{i j} e_{i j}\right]^{\frac{1}{2}}$} & I,II \\
$k$ & $\kappa \rho c_{p}$ & I,II \\
$\alpha$ & $\frac{\alpha_{0} \Delta \alpha}{\left(\left(\Delta \alpha^{1 / 3}-1\right)(1-z)+1\right)^{3}}$ & II \\
$\Gamma_{k}$ & $\frac{1}{2}\left(1+\sin \left(\pi \frac{z-z_{0}(T)}{\delta z}\right)\right)$ & I,II \\
$\delta \rho$ & $\frac{\partial \rho}{\partial F}$ & I \\
$\delta \rho_{k}$ & $\frac{\partial \rho}{\partial \Gamma_{k}}$ & I,II \\
$\tau_{i j}$ & $\eta e_{i j}$ & I,II \\
$\tau$ & {$\left[\frac{1}{2} \tau_{i j} \tau_{i j}\right]^{\frac{1}{2}}$} & I,II \\
\hline
\end{tabular}

Table 3: Parameter definitions. 


\begin{tabular}{|c|c|c|c|c|c|}
\hline model & \multicolumn{3}{|c|}{ specific characteristics } & $\mathrm{Ra}_{\text {start }}^{\text {eff }}$ & Plate \\
\hline I-a & \multicolumn{3}{|c|}{ partial melting of mantle } & & \\
\hline \multirow{3}{*}{ I-b } & \multicolumn{3}{|c|}{ melt segregation $\rightarrow$ crustal production } & $9.0 \cdot 10^{8}$ & 1,2 \\
\hline & \multicolumn{3}{|c|}{ Experiment I-a including partial melting } & & \\
\hline & \multicolumn{3}{|c|}{ of basaltic crust to form felsic material } & $6.5 \cdot 10^{6}$ & 3 \\
\hline model & $\frac{\delta \rho_{c}}{\rho_{0}}$ & $\frac{H_{e n r}}{H_{d e p l}}$ & $\mathrm{Ra}_{\text {start }}^{\text {eff }}$ & $\mathrm{Ra}_{\text {end }}^{\mathrm{eff}}$ & Plate \\
\hline II-a & 0.000 & 1 & $7.2 \cdot 10^{6}$ & $1.6 \cdot 10^{6}$ & $5 \mathrm{a}$ \\
\hline II-b & 0.005 & 1 & $7.2 \cdot 10^{6}$ & $2.1 \cdot 10^{6}$ & $5 \mathrm{~b}$ \\
\hline II-c & 0.010 & 1 & $7.2 \cdot 10^{6}$ & $1.8 \cdot 10^{6}$ & $5 \mathrm{c}$ \\
\hline II-d & 0.015 & 1 & $7.2 \cdot 10^{6}$ & $2.3 \cdot 10^{6}$ & $5 \mathrm{~d}$ \\
\hline II-e & 0.010 & 2 & $7.2 \cdot 10^{6}$ & $2.3 \cdot 10^{6}$ & 4 \\
\hline
\end{tabular}

Table 4: Numerical models used in this study and their characteristics. $\frac{\delta \rho_{c}}{\rho_{0}}$ indicates the relative intrinsic excess density of the deep layer, and $\frac{H_{\text {enr }}}{H_{\text {depl }}}$ its relative enrichment in heat producing elements relative to the rest of the mantle. The effective thermal Rayleigh numbers at the start $\left(\mathrm{Ra}_{\mathrm{start}}^{\mathrm{eff}}\right)$ and the end $\left(\mathrm{Ra}_{\text {end }}^{\text {eff }}\right)$ of the experiments are indicated, as well as a figure reference. 


\begin{tabular}{|c|c|c|}
\hline symbol & property & value/unit \\
\hline$B_{1}$ & diffusion creep prefactor & Pas \\
\hline$B_{2}$ & dislocation creep prefactor & $\mathrm{Pa}^{\mathrm{n}_{2}} \mathrm{~S}$ \\
\hline$C_{0}$ & cohesion factor & $0 \mathrm{~Pa}$ \\
\hline$E_{1}$ & diffusion creep activation energy & $270 \cdot 10^{3} \mathrm{Jmol}^{-1}$ \\
\hline$E_{2}$ & dislocation creep activation energy & $485 \cdot 10^{3} \mathrm{Jmol}^{-1}$ \\
\hline$e_{i j}$ & strain rate tensor & $\mathrm{s}^{-1}$ \\
\hline$e$ & second invariant of the strain rate tensor & $\mathrm{s}^{-1}$ \\
\hline$f(F)$ & composition dependent viscosity prefactor & \\
\hline$n_{1}$ & diffusion creep stress exponent & 1 \\
\hline$n_{2}$ & dislocation creep stress exponent & 3.25 \\
\hline$n_{y}$ & yield exponent & 10 \\
\hline$R$ & gas constant & 8.341. $\mathrm{Jmol}^{-1} \mathrm{~K}^{-1}$ \\
\hline$V_{1}$ & diffusion creep activation volume & $6 \cdot 10^{-6} \mathrm{~m}^{3} \mathrm{~mol}^{-1}$ \\
\hline$V_{2}$ & dislocation creep activation volume & $17.5 \cdot 10^{-6} \mathrm{~m}^{3} \mathrm{~mol}^{-1}$ \\
\hline$\dot{\varepsilon}$ & strainrate & $\mathrm{s}^{-1}$ \\
\hline$\dot{\varepsilon}_{y}$ & yield strainrate & $10^{-15} \mathrm{~s}^{-1}$ \\
\hline$\eta$ & viscosity & Pas \\
\hline$\eta_{0}$ & reference viscosity & $10^{20} \mathrm{Pas}$ \\
\hline$\eta_{y}$ & yield viscosity & Pas \\
\hline$\mu$ & friction coefficient & 0.03 \\
\hline$\sigma_{n}$ & normal stress & $\mathrm{Pa}$ \\
\hline$\tau_{i j}$ & deviatoric stress tensor & $\mathrm{Pa}$ \\
\hline$\tau$ & $\begin{array}{l}\text { second invariant of } \\
\text { the deviatoric stress tensor }\end{array}$ & $\mathrm{Pa}$ \\
\hline$\tau_{y}$ & yield stress & $\mathrm{Pa}$ \\
\hline
\end{tabular}

Table 5: Definitions and values of rheological parameters for Experiment I. 
(a) $<\mathrm{T}>\left({ }^{\circ} \mathrm{C}\right)$
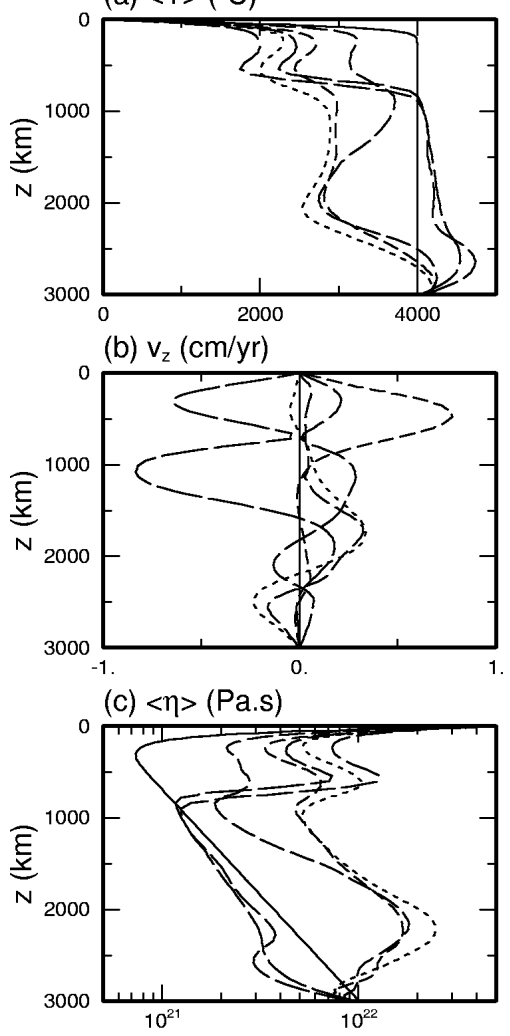

(d) $\langle\mathrm{T}\rangle\left({ }^{\circ} \mathrm{C}\right)$

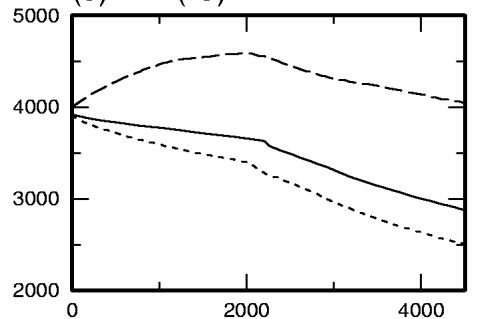

(e) $<v_{\mathrm{rms}}>(\mathrm{cm} / \mathrm{yr})$
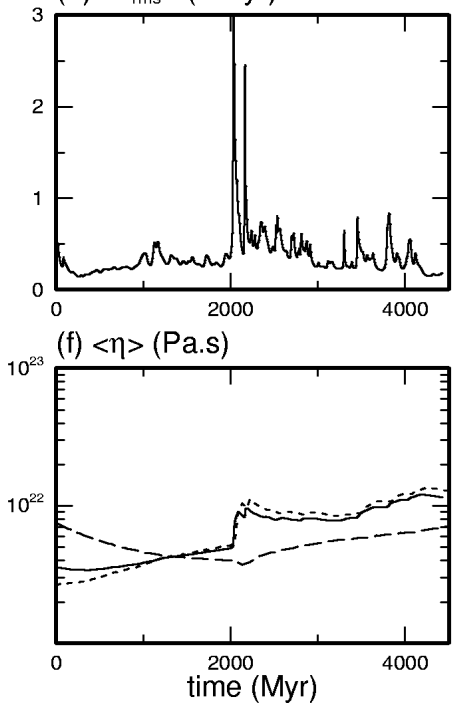

(g) $<Q_{\text {surf }}>\left(\mathrm{mW} / \mathrm{m}^{2}\right)$

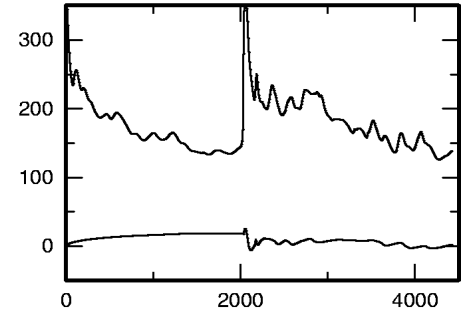

(h) B (-)

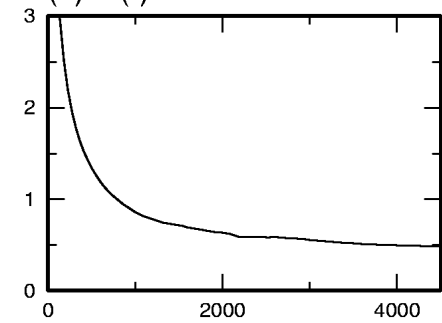

(i) ENT (\%)

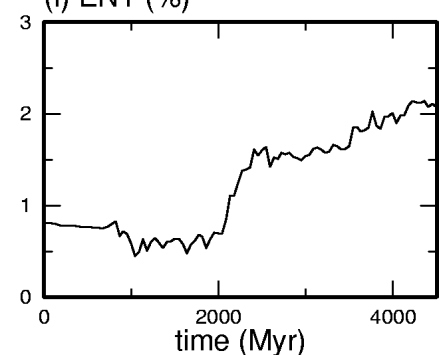

Figure 1: Time series and profiles of several global quantities for the reference model II-e. Panels (a)-(c) show vertical profiles of the horizontally averaged temperature, the vertical flow velocity at $\mathrm{x}=0.5$, and the horizontally averaged viscosity, respectively, at $893 \mathrm{Myr}$ intervals (decreasing dash size corresponds to increasing model time). Panels (d)-(f) show time series of the volume averaged temperature, root mean square velocity, and volume averaged viscosity, respectively. Dashed and dotted curves in panels (d) and (f) indicate values for the enriched layer and the depleted mantle, respectively. Panels (g)-(i) show mean surface heat flux (top curve) and mantle to core heat flux (bottom curve), the buoyancy parameter $B$, and entrainment, respectively. 

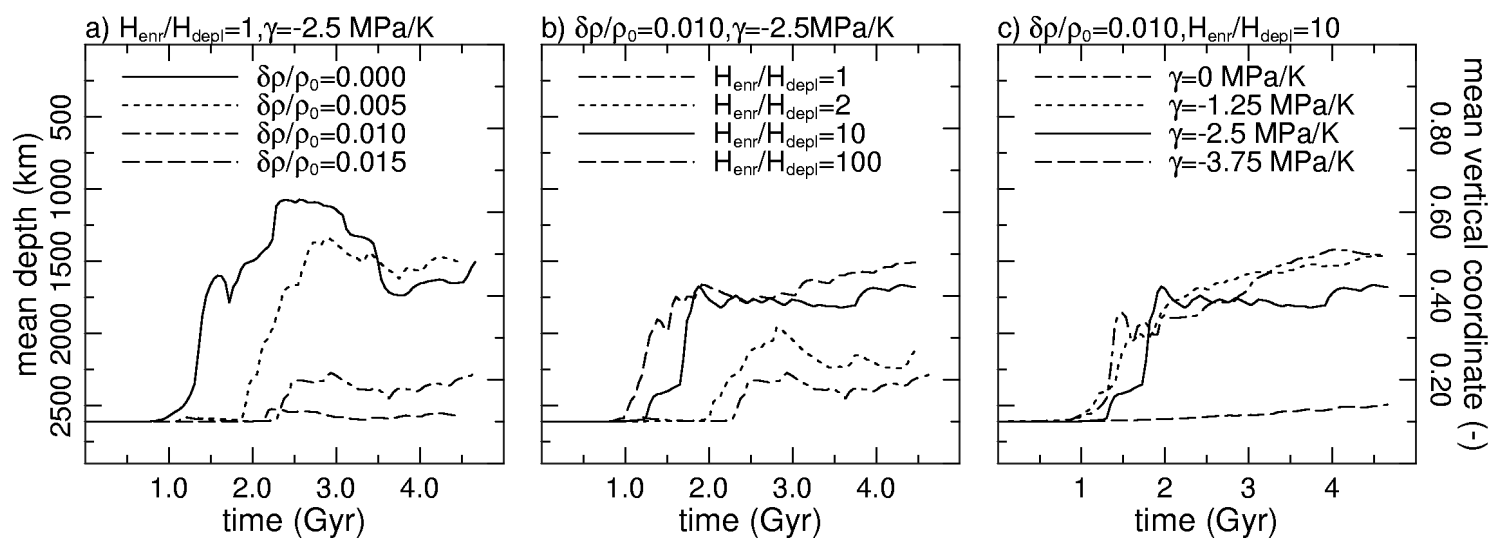

Figure 2: Mean depth/vertical coordinate of dense tracer population according to expression (11), as a function of time: a) Uniform distribution of heat productivity; b) dense layer enriched in heat producing elements; c) sensitivity to the postspinel Clapeyron slope. 


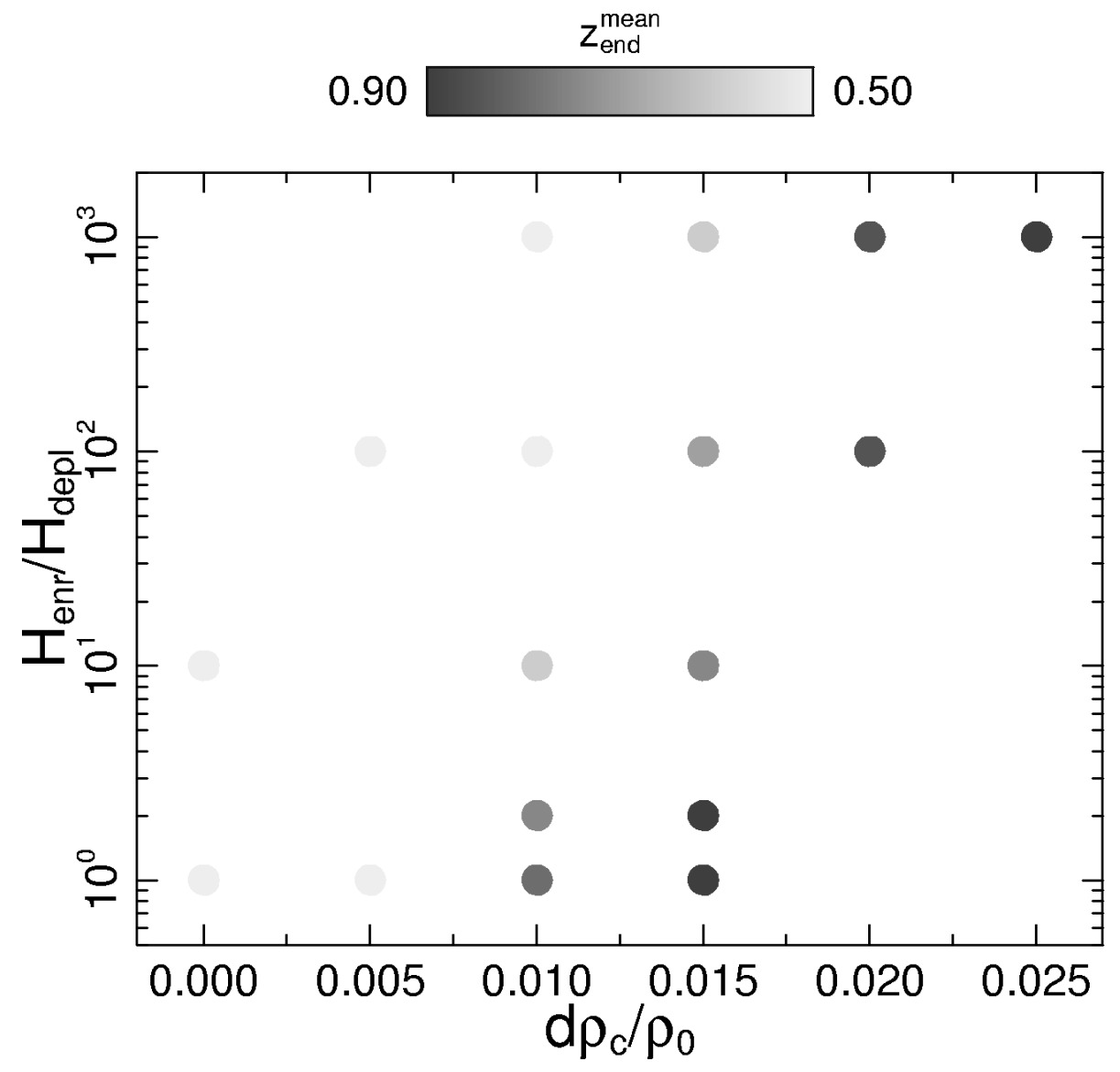

Figure 3: Stability of a deep dense layer as a function of chemical density contrast (horizontal axis) and internal heating of the layer (vertical axis). The grey scale of the dots shows the mean depth of deep layer tracers after 4.5 Gyr of model evolution, according to equation (11). Dark grey dots indicate stable configurations, light grey dots show complete mixing. 

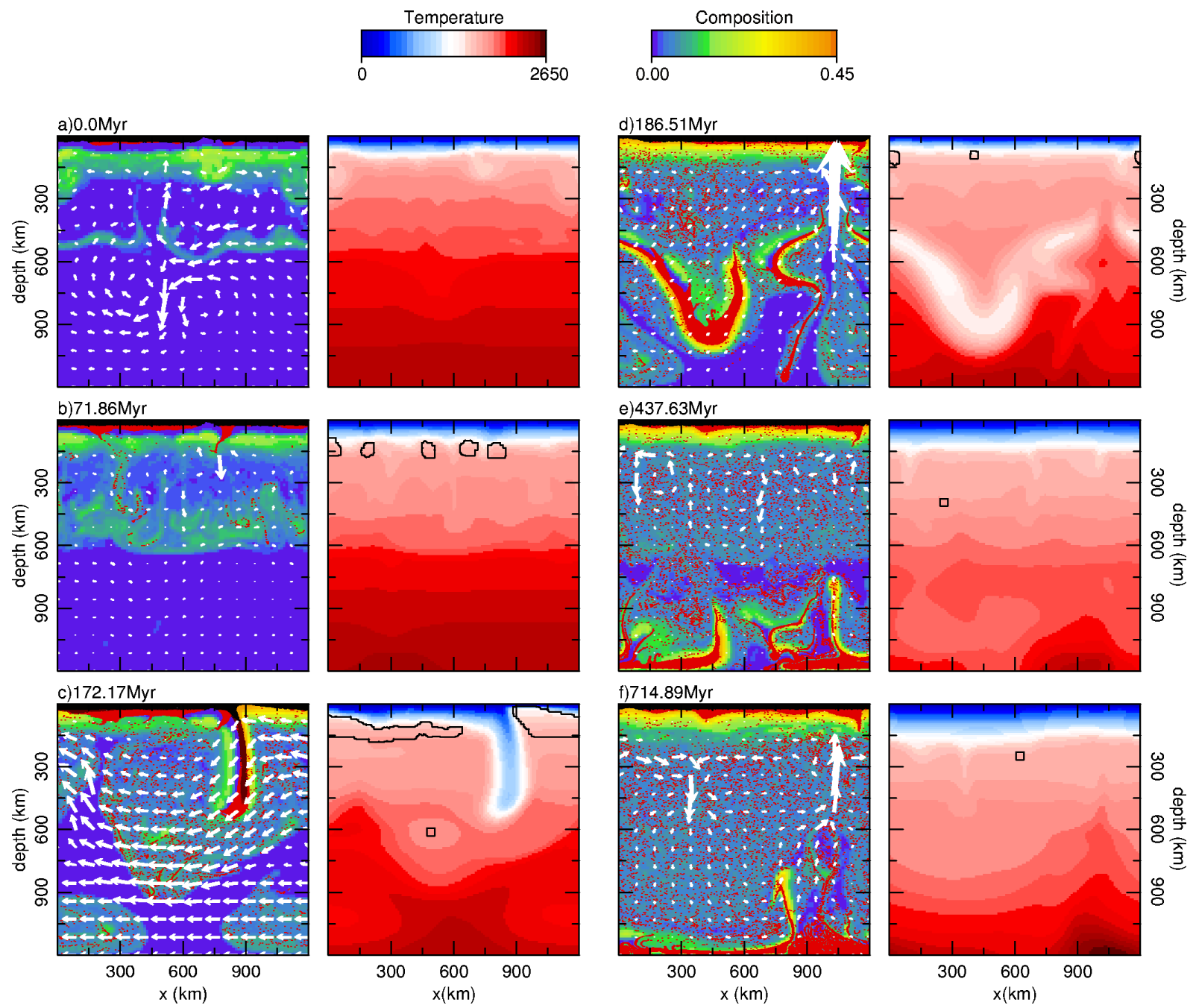

Plate 1: Secular evolution of the composition (left) and temperature (right) fields of model I-a. The color scale in the composition plots indicates the degree of depletion of mantle peridotite. Black indicates basalt, and red indicates eclogite. The arrows show the instantaneous flow field. The contours in the temperature frames indicate regions of partial melting. 


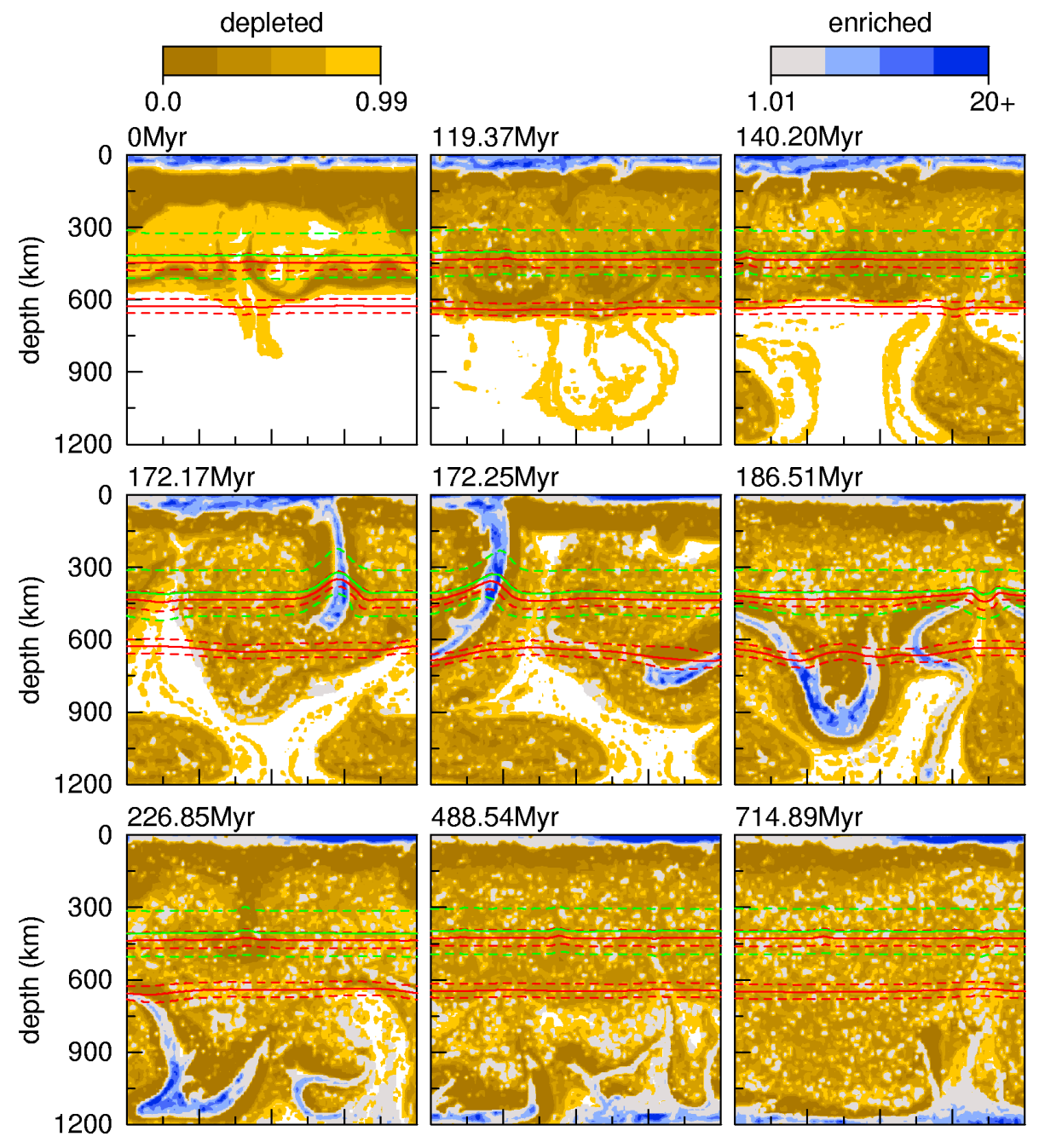

Plate 2: Incompatible trace element concentrations, corrected for radioactive decay, at nine different times in the evolution of model I-a (see also Plate 1). Pristine material is white, depleted material is yellow and enriched material is blue/grey. Curves indicate phase boundaries at $50 \%$ (solid) and 10 and $90 \%$ (dashed) of the transition for peridotitic (red) and basaltic (green) compositions. 

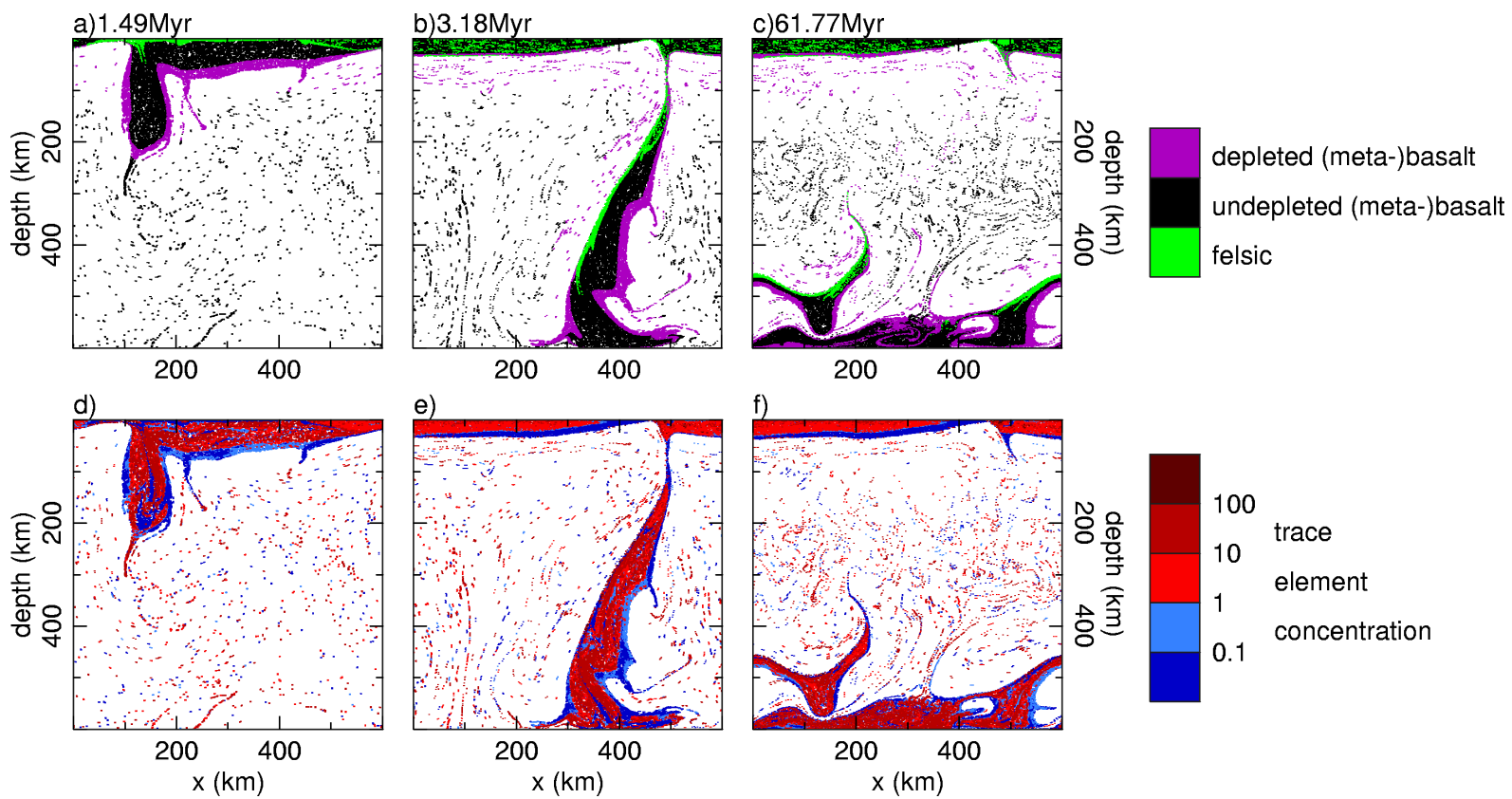

Plate 3: Non-mantle material type (a-c) and trace element concentration, relative to pristine mantle peridotite (d-f) of model I-b, which is started from a 600x600 clipping from the upper right corner of the 1200x1200 km domain of model I-a, some time between (b) and (c) of Plate 1. 

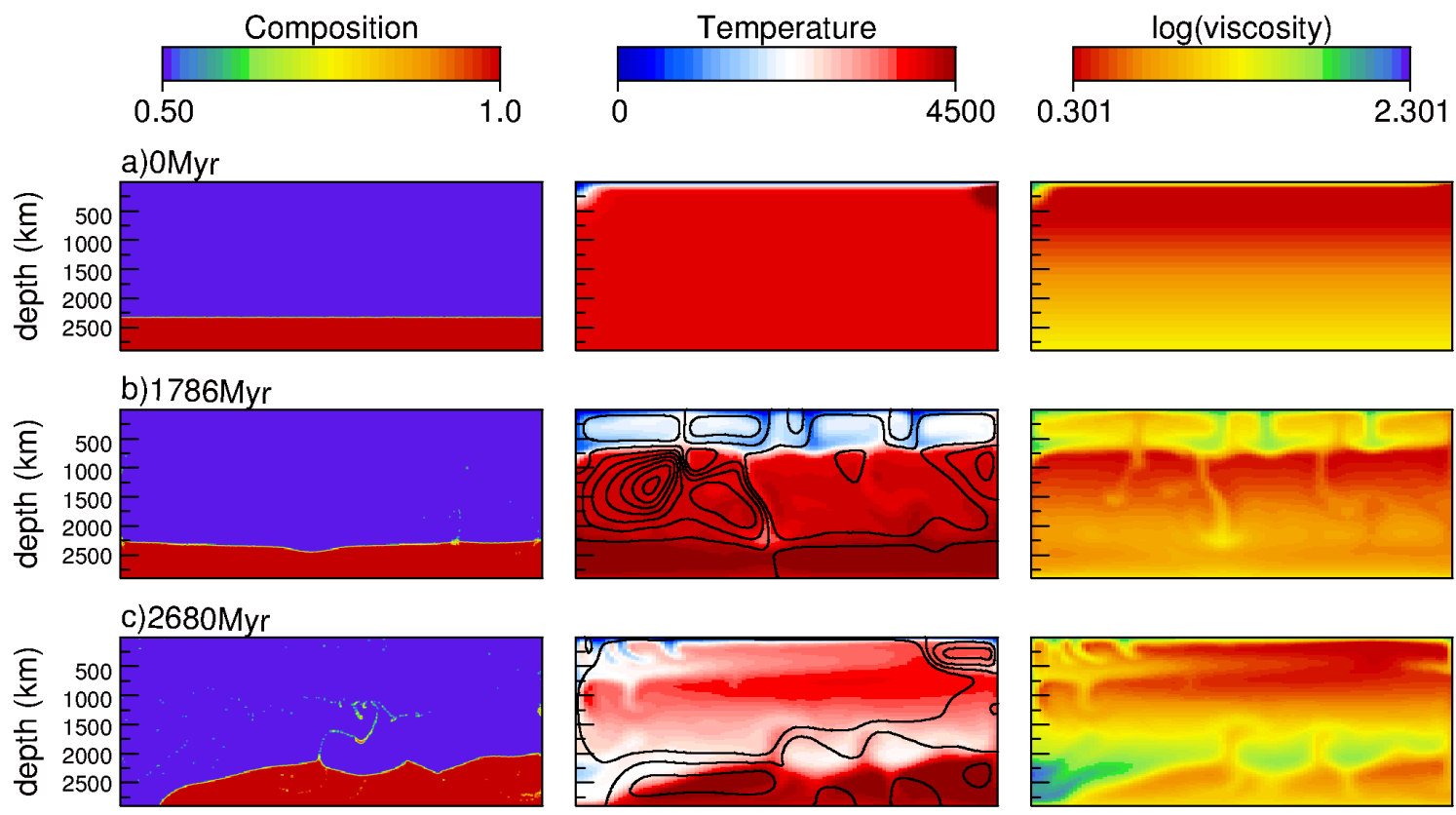

\section{d) $3573 \mathrm{Myr}$}
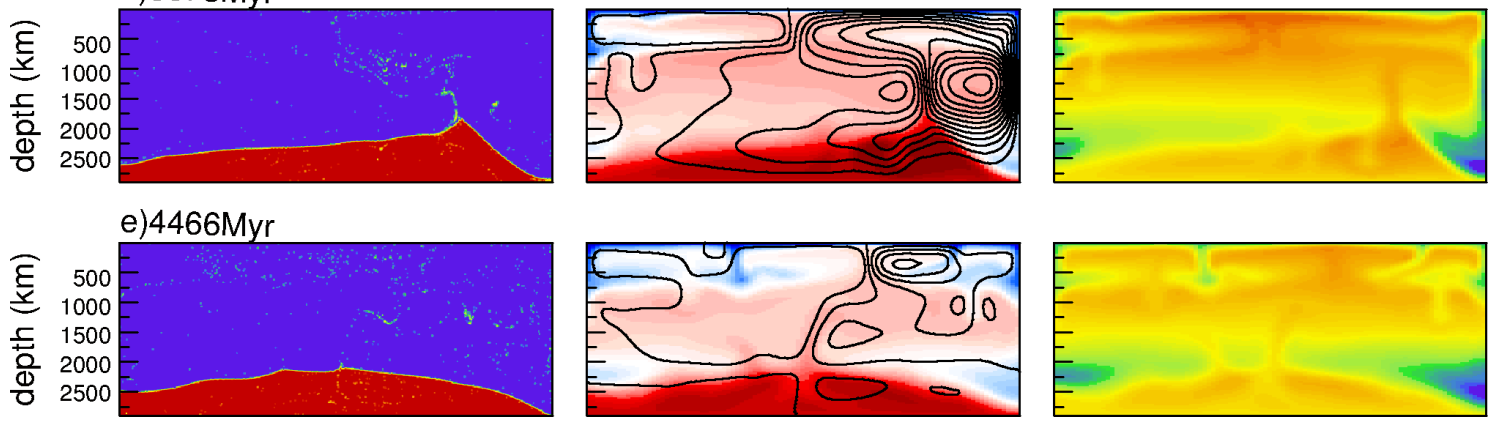

Plate 4: Snapshots at five subsequent times of model II-e, showing the composition field, the temperature field with stream lines, and the viscosity field (effective values range from $10^{21}$ Pas (red) to $10^{23}$ Pas (blue)). 

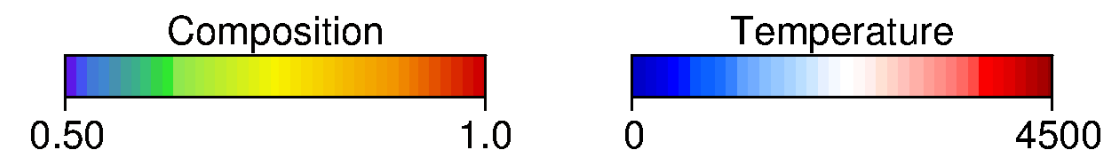

a)
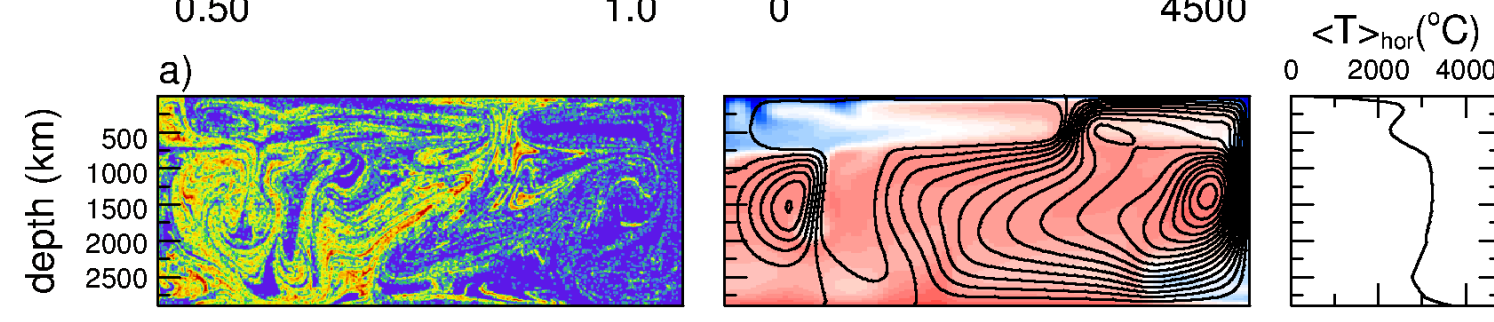

b)
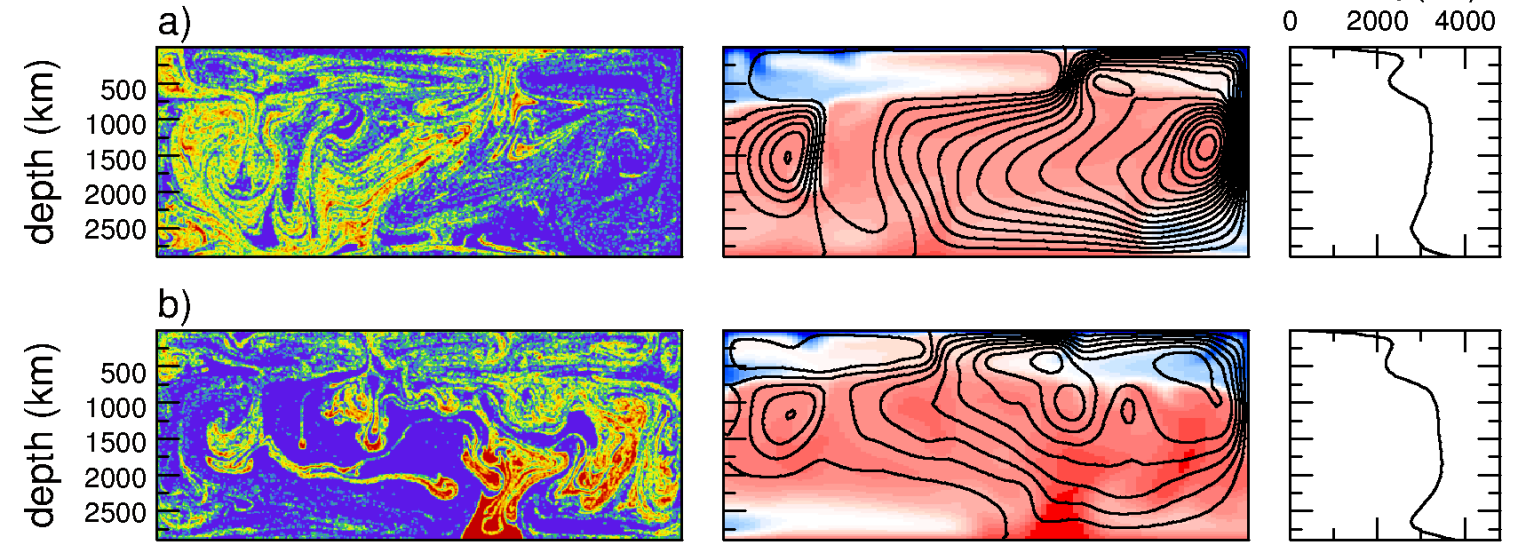

c)
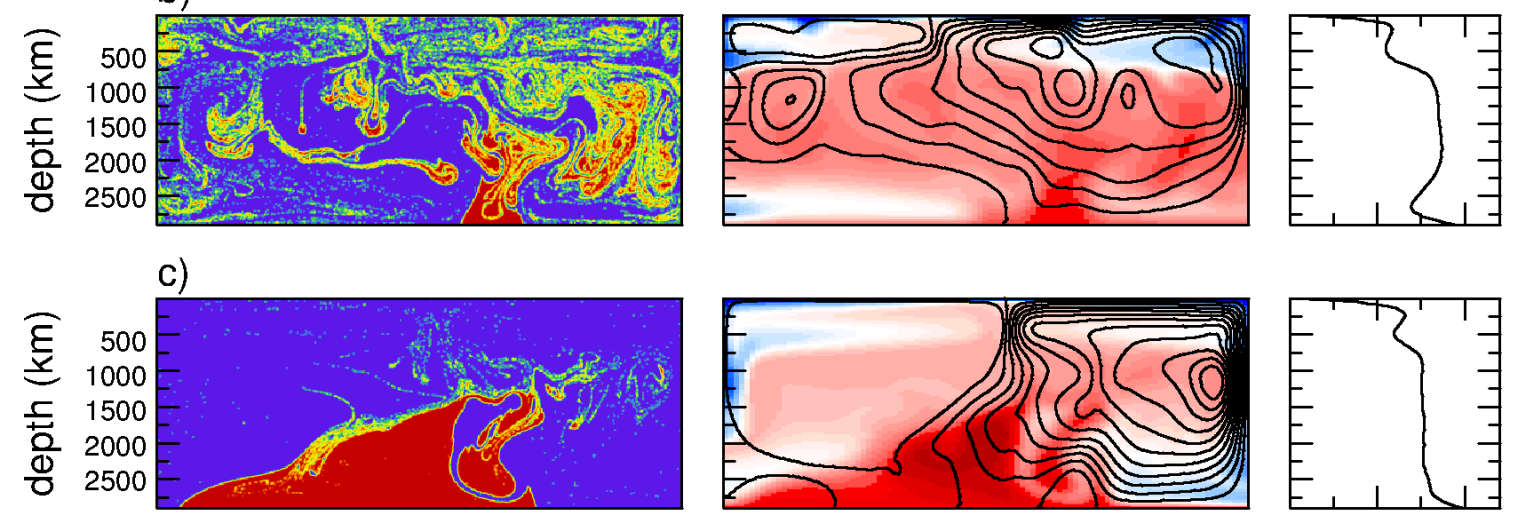

d)
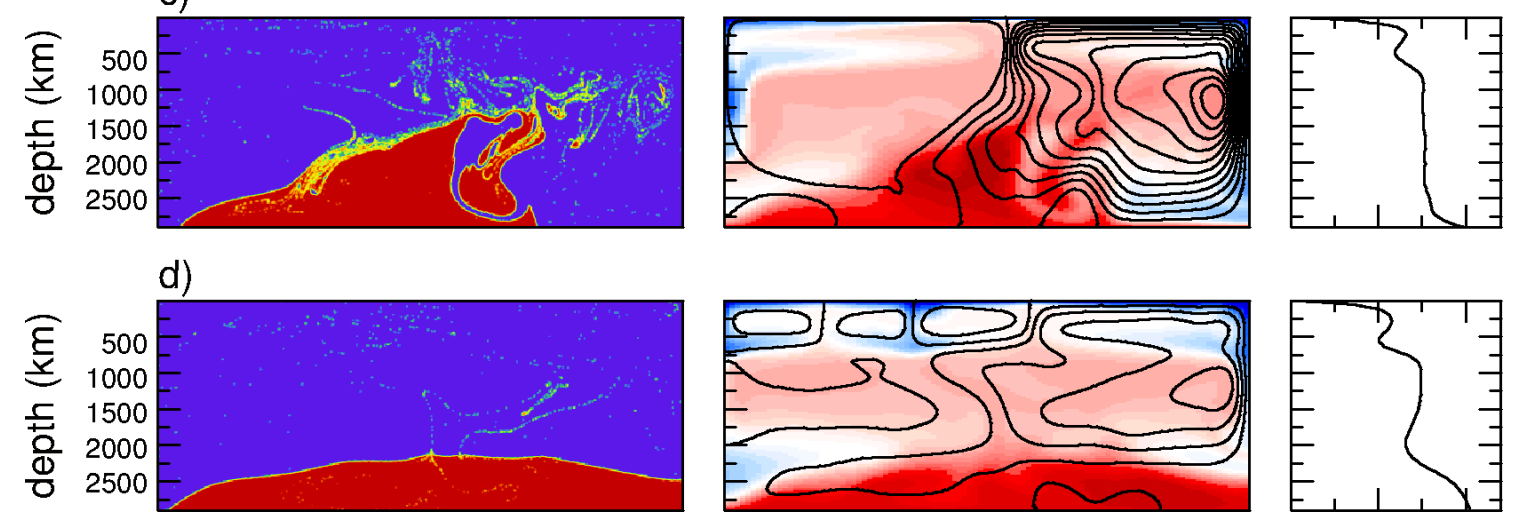

Plate 5: Snapshots after 4.5 billion years of model evolution of the composition field, temperature and flow field (stream lines), and horizontally averaged temperature profiles for models II-a,b,c, and d. 

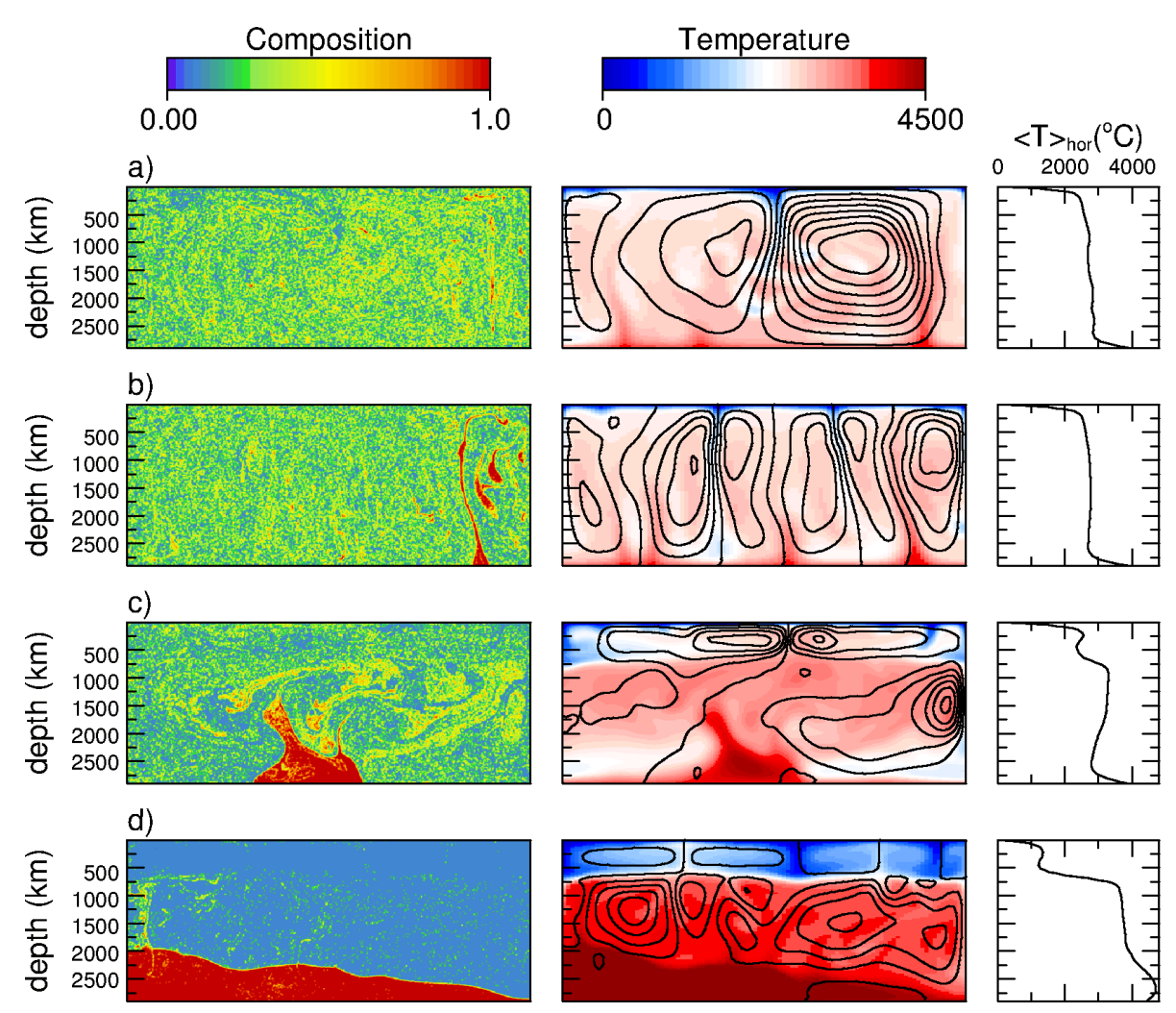

Plate 6: Mantle composition, temperature and flow field after approximately 4.4 billion years of evolution, for four different magnitudes of the postspinel Clapeyron slope. a) $\gamma=0 \mathrm{MPa} / \mathrm{K}, \mathrm{b}$ ) $\gamma=-1.25 \mathrm{MPa} / \mathrm{K}$, c) $\gamma=-2.5 \mathrm{MPa} / \mathrm{K}, \mathrm{d}) \gamma=-3.75 \mathrm{MPa} / \mathrm{K}$. 